\title{
Identification of the sources of inertia-gravity waves in the Andes Cordillera region
}

\author{
A. Spiga, H. Teitelbaum, and V. Zeitlin \\ Laboratoire de Météorologie Dynamique, École Normale Supérieure, 24 rue Lhomond, 75231 Paris Cedex 05, France
}

Received: 15 May 2008 - Revised: 11 July 2008 - Accepted: 23 July 2008 - Published: 5 September 2008

\begin{abstract}
Four major sources of inertia-gravity waves are known in the Earth atmosphere: upper-tropospheric jetstreams, lower-tropospheric fronts, convection and topography. The Andes Cordillera region is an area where all of these major sources are potentially present. By combining ECMWF and NCEP-NCAR reanalysis, satellite and radiosoundings data and mesoscale WRF simulations in the Andes Cordillera region, we were able to identify the cases where, respectively, the jet-stream source, the convective source and the topography source are predominantly in action. We retrieve emitted wave parameters for each case, compare them, and analyse possible emission mechanisms. The WRF mesoscale model shows very good performance in reproducing the inertia-gravity waves identified in the data analysis, and assessing their likely sources.
\end{abstract}

Keywords. Meteorology and atmospheric dynamics (Mesoscale meteorology; Synoptic-scale meteorology; Waves and tides)

\section{Introduction}

The key role of the gravity waves in the dynamical, transport and mixing properties of the atmosphere is well-known (Andrews et al., 1987; Fritts and Alexander, 2003). The identification and quantification of sources of gravity waves (GW hereinafter) is thus a task of primary importance and has been undertaken in a number of studies. As was highlighted by Lane and Knievel (2005) in the particular case of deep convective clouds, these studies usually distinguish, according to the standard mesoscale terminology of Orlanski (1975), the high-frequency gravity waves in the meso- $\beta$ and meso$\gamma$ scales on the one hand, and on the other hand the lowfrequency gravity waves and inertia-gravity waves (IGW in

Correspondence to: A. Spiga

(spiga@lmd.ens.fr) what follows) in the meso- $\alpha$ and synoptic scales. The present study focuses on the IGW, with frequencies close to the inertial frequency. Four major sources of IGW are known: lowertropospheric fronts, upper-tropospheric jet streams, convection and topography.

Using aircraft measurements, Fritts and Nastrom (1992) and Nastrom and Fritts (1992) showed that the variances of horizontal velocity and temperature are enhanced in the vicinity of fronts and jets, as well as near mountains. The evidence that the IGW activity is intense near the fronts was further supported by Eckermann and Vincent (1993) who used radar measurements over southern Australia. Numerical evidence for the emission of IGW during the frontogenesis process was provided by Snyder et al. (1993) and Reeder and Griffiths (1996).

The IGW production by the jet stream was reported by Plougonven et al. (2003) using the data obtained during the Fronts and Atlantic Storm-Track EXperiment (FASTEX) campaign. The IGW emission by jets is usually associated with the process of geostrophic adjustment, as shown in the studies by Uccellini and Koch (1987), Thomas (1999), Moustaoui et al. (1999), Pavelin et al. (2001), Hertzog et al. (2001), using data analysis, and in numerical experiments by Van Tuyl and Young (1982), Fritts and Luo (1992), O'Sullivan and Dunkerton (1995), Plougonven and Snyder (2007). IGW emitted by this mechanism are mostly lowfrequency waves. A good indicator of the adjustment regions is the value of the Lagrangian Rossby number defined as the ratio of the ageostrophic horizontal velocity to the full horizontal velocity (additional details on this diagnostic and the validation of the method can be found in Plougonven et al., 2003, and Zhang et al., 2000).

The IGW activity above the deep convection was addressed in a number of studies: Alexander and Pfister (1995), Sato et al. (1995), Dewan et al. (1998), Vincent and Alexander (2000) and Alexander and Vincent (2000). Due to the variety of convective structures, different mechanisms resulting

Published by Copernicus Publications on behalf of the European Geosciences Union. 
in buoyancy perturbations at different scales may be in action, which explains the variety of parameters of IGW and GW emitted due to convection. Three emission mechanisms are usually associated with convection: a bulk release of the latent heat (Piani et al., 2000), the "obstacle effect" produced by the convective column on the stratified shear flow above (Pfister et al., 1993), and the "mechanical pump" effect due to the oscillatory motions of the localized momentum source (Fovell et al., 1992; Lane et al., 2001). The frequency and structure of the IGW emitted by each mechanism largely vary, although the "mechanical pump" seems to produce only high-frequency GW.

The topography as a source of IGW was put forward by Nastrom and Fritts (1992) and by Scavuzzo et al. (1998). As is well known, the flow over mountains, especially when the thermal stratification is statically stable, may lead to the excitation of gravity waves with high intrinsic frequency (e.g. Gossard and Hooke, 1975). These waves may propagate upward to high altitudes in the atmosphere before breaking and dissipating (as their amplitude increases exponentially with height). We call in what follows "mountain waves" this particular kind of gravity waves, which exhibit typical patterns of alternating regions of positive and negative vertical velocity and strong deformation of isentropes often resulting in breaking. Scavuzzo et al. (1998), using data from the PYRénées EXPeriment (PYREX), identified IGW with low intrinsic frequency propagating upward and downward from the level where the amplitudes of initial mountain waves are large. These authors suggested that the observed IGW resulted from the geostrophic adjustment of the large-scale flow due to the high amplitude and, eventually, the breaking of the main mountain wave.

The above-mentioned major sources of the IGW emission are often combined in nature. For quantification purposes, it is desirable to find some clear manifestations of each of them separately and compare the characteristics of the emitted waves. This is the goal of the present study. For this purpose, we choose the Andes Cordillera region where at least three of the main sources (jet-stream, topography and convection) are acting in a recurrent way. We combine different technical tools in order to identify and quantify the IGW emission events corresponding to each source.

\section{Investigation techniques}

\subsection{Reanalyses}

A first rough choice of relevant dates is made using the National Centers for Environmental Prediction - National Center for Atmospheric Research (NCEP-NCAR) climatologies, available from the International Research Institute for climate and society/Lamont-Doherty Earth Observatory (IRI/LDEO) Climate Data Library (website: http://ingrid. ldeo.columbia.edu). As indicators of, respectively, mountain wave, and jet-stream sources, we use the climatologies of the zonal drag due to gravity wave and of the winds and vorticity.

The European Center for Medium-range Weather Forecast (ECMWF) reanalysis at higher resolution than the online NCEP/NCAR reanalysis are then used to obtain more details on the synoptic situation in a given region. The ECMWF data are giving information mainly on the possible jet-stream or front sources of the IGW. They are also used to identify the strong near-surface winds required for generation of highamplitude mountain waves close enough to breaking, which possibly lead to the secondary IGW emission.

\subsection{Radiosoundings}

Previous studies (e.g. Vincent and Alexander, 2000; Guest et al., 2000; Moustaoui et al., 1999) have shown that radiosoundings could be used for detection of low-frequency inertia-gravity waves and retrieval of their parameters. Radiosoundings of a good quality are available from the University of Wyoming database (website: http://weather.uwyo. edu/upperair/sounding.html) for two stations in the region: Santo Domingo (33.65 S, $71.61 \mathrm{~W}$ ) and Salta Aero (24.85 S, $65.48 \mathrm{~W})$. The radiosoundings which we use contained at least 80 points in the vertical.

In order to separate the perturbation from the mean field, various filters were applied. The main filter of this study is a non-recursive bandpass digital filter using the Kaiser window (see details in the Appendix of Scavuzzo et al., 1998). The basic wavelength selection window is $[1.5,8] \mathrm{km}$ (the wavelength window is the only tunable parameter). This filter requires evenly spaced data points; continuous profiles of wind with $100 \mathrm{~m}$ vertical resolution are obtained from the raw data using the classic cubic spline interpolation method described in Press et al. (1992).

Alternative filters not requiring evenly spaced data points were applied as well. Least-square polynomial fit (5th to 7thorder) of the raw profile were performed to obtain a "mean" wind field. The perturbation profile was then defined by substraction of the mean wind profile from the raw wind profile. Contrary to other methods, no bandpass filtering is required to obtain such perturbation profile. However, associating the mean profile with the smooth least-square polynomial fit allows mostly for the identification of the shortest wavelength signals present in the profile. Nevertheless, polynomial filters are useful to check possible biases of the cubic spline interpolation. The latter is known to produce spurious addition to the signal. By comparing the results obtained with different filters, we observed no significant contamination.

\subsection{Wavelet analysis}

The vertical perturbation profiles obtained from the radiosoundings data provide a rather good quantitative estimate of the vertical wavelength of the IGW. An independent estimate of the vertical wavelength can be obtained from the 
wavelet analysis of the splined non-filtered vertical profile of the zonal and meridional winds. Wavelet software is provided by C. Torrence and G. Compo (Torrence and Compo, 1998; website: http://paos.colorado.edu/research/wavelets). These authors show the quantitative relevance of the wavelet analysis, which, in addition to statistical significance tests, is able to determine the dominant wavelength in a profile from the maximum of the wavelet transform located inside the cone-of-significance area. In the present study, the wavelet analysis is mainly used for two purposes: a priori identification of the different wave components present in the signal, and a posteriori verification of the profile analysis (and of the method of filtering). In some cases, a preliminary wavelet analysis provides useful clues as to choose a more selective filtering window than the wide $[1.5,8] \mathrm{km}$ one, which leads to clearer IGW detection from the velocity perturbations profiles. The wavelet function chosen in this paper is the Morlet wavelet function, but tests were also carried out with the Paul and the DOG ("Mexican Hat") functions, and gave similar results.

\subsection{Satellite data}

To detect the presence or absence of convective activity, the satellite data are used. The images in the IR channel of the National Oceanic and Atmospheric Administration Defense Meteorological Satellites Program (NOAA/DMSP, website: http://spidr.ngdc.noaa.gov/spidr/index.jsp) give rough diagnostics of the cloud masses. Whenever possible, the distributions of the temperature at the cloud tops are extracted from the data provided by the MODerate resolution Imaging Spectroradiometer (MODIS) on satellite TERRA and by the Geostationary Operational Environmental Satellites (GOES). These data are provided by the Service d'Archivage et de Traitement Météorologique des Observations Spatiales (SATMOS database from INSU/METEO-FRANCE).

\subsection{Mesoscale numerical simulations}

Three-dimensional mesoscale simulations using the Weather Research Forecast model (WRF, Skamarock et al., 2005, website: www.mmm.ucar.edu/wrf/users) can be performed firstly to access the scales in the analysis not reached by the ECMWF, and secondly to check whether the model reproduces the IGW identified by the data analysis, or whether the model is able to help interpreting wave sources more accurately than the data analysis.

WRF is a new generation mesoscale model, including fully compressible nonhydrostatic equations, mass-based terrain-following coordinates, nesting and map projection options, complete and up-to-date dynamical solver, and several choices of physical parametrizations in what concerns microphysics, convection, planetary boundary layer, radiation, turbulence, and land influence. In the present study, we use the version 2.2 two-way interactive nesting Advanced
Research WRF (ARW) core with Arakawa C-grid staggering and Runge-Kutta 3rd order time-integration scheme. The following physical settings are chosen for all performed simulations: Rapid Radiative Transfer Model (RRTM) for longwave radiation, Dudhia MM5 scheme for shortwave radiation, Yonsei University (YSU) scheme for planetary boundary layer, MM5 simple 5-layer land-surface model, and Monin-Obukhov scheme for surface-layer interactions. Convection parameterization is carried out with the Kain-Fritsch new Eta scheme, which uses a simple cloud model with moist updrafts and downdrafts, including the effects of detrainment, entrainment, and relatively simple microphysics. This scheme is completed with Ferrier new Eta microphysics scheme.

The WRF simulations are performed in a square domain of $2000 \times 2000 \mathrm{~km}$ centered at the location of the radiosoundings, with a spatial resolution of $20 \mathrm{~km}$ in the horizontal. The simulations also feature a $670 \times 670 \mathrm{~km}$ nested domain (nesting is set in interactive two-way mode), centered at the location of the radiosoundings, with improved spatial resolution $(6.7 \mathrm{~km})$. These horizontal resolution choices are consistent with the focus of this paper on the inertia-gravity waves. Possible sources and emitted IGW are accurately described in the meso- $\alpha$ scales. Thus, the gravity wave spectrum in the mesoscale simulations is limited to waves with horizontal wavelengths above $60 \mathrm{~km}$ (a strict minimum of three grid points is required to form a consistent wave signal). Furthermore, the resolved spectrum experiences a sharp drop-off of energy at the highest wavenumbers, due the numerical filters in the model: the effective resolution is in reality 4-5 grid points. In the present study, inertia-gravity waves are correctly resolved, as the simulations include a nested domain with finer spatial resolution, centered in the area of interest.

Time step for advection scheme is cautiously set to $30 \mathrm{~s}$, to ensure the numerical stability of the mesoscale simulations in a real-case environment with steep topographical gradients and possible intense non-hydrostatic motions. In the vertical, 61 sigma-levels corresponding to pressures between $1000 \mathrm{hPa}$ and $10 \mathrm{hPa}$ are taken, which is equivalent to a vertical resolution of $500 \mathrm{~m}$ (the sigma-levels are chosen to have almost equally spaced altitudes above $3 \mathrm{~km}$ altitude). The upper level gravity wave diffusive damping is included on a "sponge layer" of $5 \mathrm{~km}$ thickness at the top of the model. The fields at the horizontal boundaries of the integration domain are initialized with the help of ECMWF meteorological fields (taken each $6 \mathrm{~h}$ ). The model includes temporal and spatial interpolations of these lateral boundary conditions, as well as a relaxation zone at the domain boundaries, which prevents the prescribed meteorological fields at the lateral boundaries to have sharp gradients and to trigger spurious waves. To ensure that the model has reached equilibrium at the time we would like to compare the radiosoundings with the simulated profiles, the simulations are started $36 \mathrm{~h}$ before this time (and ended $12 \mathrm{~h}$ later). 

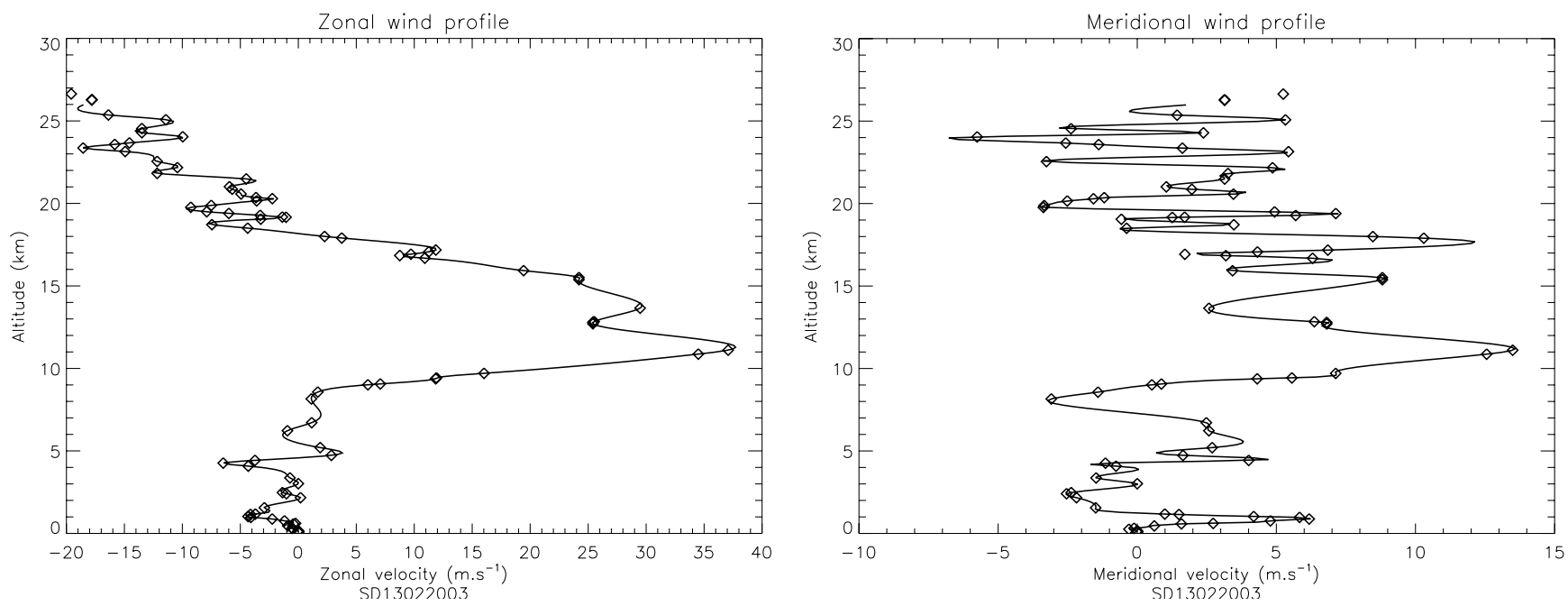

Fig. 1. Case 1: Santo Domingo radiosounding. Vertical profile of the wind velocity $\left(\mathrm{m} \mathrm{s}^{-1}\right)$. Diamonds correspond to sounding measurements. Full line is a cubic spline interpolation with vertical resolution of $100 \mathrm{~m}$. Left: Zonal wind profile. Right: Meridional wind profile.
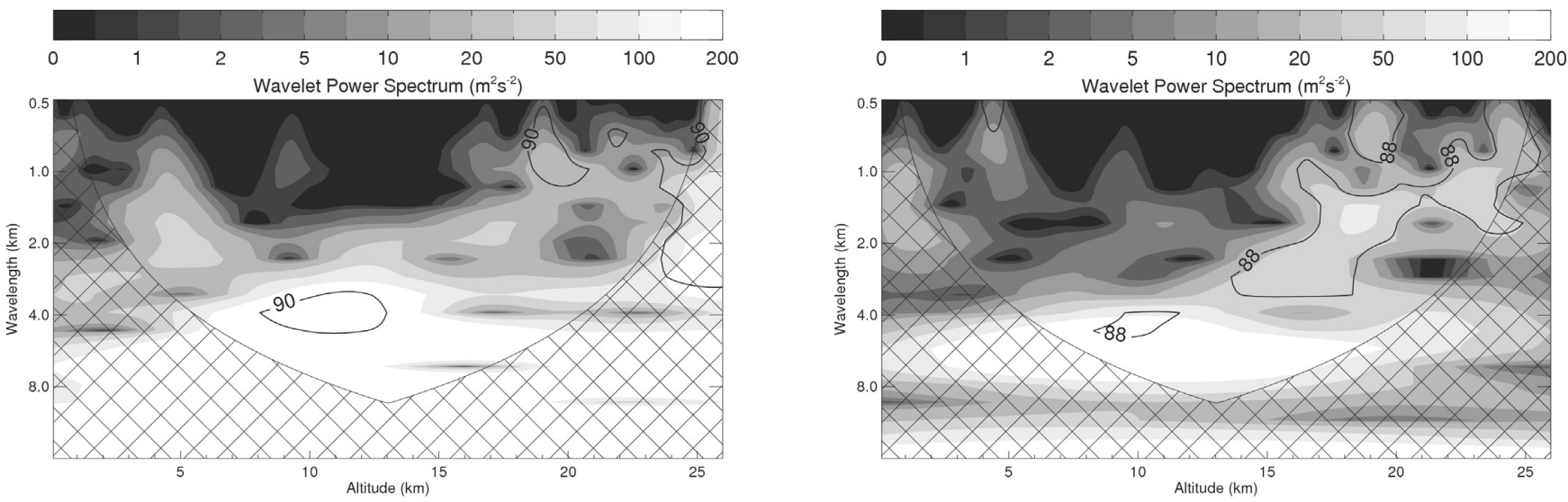

Fig. 2. Case 1: Santo Domingo radiosounding. Morlet wavelet analysis of the splined vertical velocity profiles by Torrence and Compo (1998) method. Power spectrum $\left(\mathrm{m}^{2} \mathrm{~s}^{-2}\right.$ ) with level of significance above $90 \%$ (zonal component) and above $88 \%$ (meridional component) for dominant wavelengths and their locations. Hashed regions are out of the cone-of-significance, and should not be taken into account. Left: Zonal wind. Right: Meridional wind.

The WRF simulations provide detailed information on the atmospheric processes involved (or not involved) in the IGW generation and served, at the same time, as validations of the WRF model itself. Plougonven and Snyder (2007) have demonstrated the ability of the model to consistently reproduce IGW in an idealized case of baroclinic life cycle. Using the WRF model in real cases of plausible IGW emission provides an additional test.

\section{The case studies}

In this section, we present three typical events of IGW emission. In each case, we found that a single source was largely dominating. A fourth example of sources acting simultaneously is given at the end of the paper. Note that to consistently compare the various datasets, log-pressure altitudes are derived from pressure vertical coordinates using a scale height of $H=6.1 \mathrm{~km}$ and a reference pressure of $p_{0}=1000 \mathrm{hPa}$. 

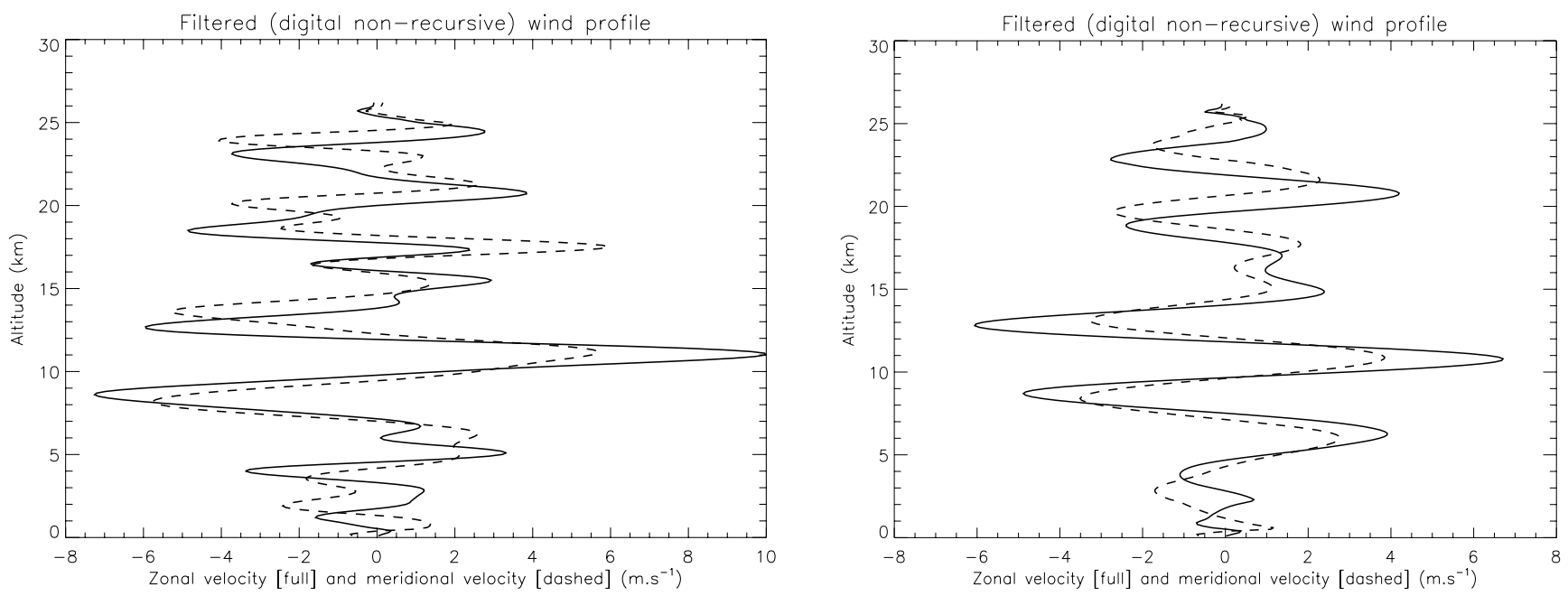

Fig. 3. Case 1: Santo Domingo radiosounding. Vertical profiles of velocity perturbations $\left(\mathrm{ms}^{-1}\right)$. Full line: zonal wind, dashed line: meridional wind. Left: Non-recursive digital filter with wide bandpass window of $[1.5,8] \mathrm{km}$. Right: Non-recursive digital filter with narrower bandpass window of $[3,6] \mathrm{km}$. The choice of this filtering window is based on the Fig. 2 results.
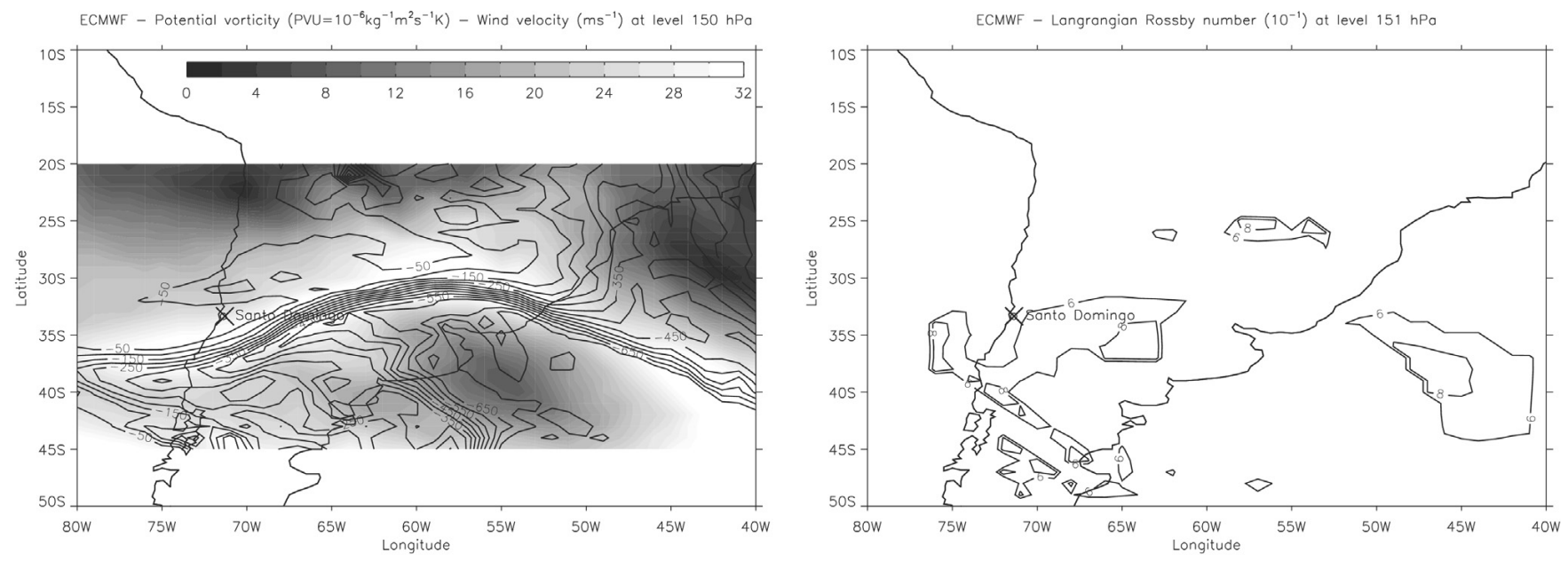

Fig. 4. Case 1: Results of the ECMWF reanalysis at the $150 \mathrm{hPa}$ level (altitude $\sim 11.6 \mathrm{~km}$ ). The Santo Domingo location is marked by the cross. Left: Contours: potential vorticity field (in PVU, $1 \mathrm{PVU}=10^{-6} \mathrm{Km}^{2} \mathrm{~kg}^{-1} \mathrm{~s}^{-1}$ ). Levels of grey: wind velocity (in m s${ }^{-1}$ ). Right: Lagrangian Rossby number contours. For clarity, only the values of the LR number above the threshold 0.4 and in areas of wind amplitudes exceeding $25 \mathrm{~m} \mathrm{~s}^{-1}$ are displayed.

\subsection{A case of the jet-stream source}

\subsubsection{Radiosounding data}

This case corresponds to the Santo Domingo (33.65 S, $71.61 \mathrm{~W}$ ) radiosounding of 13 February 2003, 12:00 UTC (referred as case 1). The corresponding value of the Coriolis parameter is $8.1 \times 10^{-5} \mathrm{~s}^{-1}$. The radiosoundings data are available for 82 levels almost uniformly distributed between 0 and $27 \mathrm{~km}$. The wind velocity profile, Fig. 1, exhibits a well pronounced zonal jet, in the altitude range of 9 to $15 \mathrm{~km}$, with a maximum at about $11 \mathrm{~km}$.
The wavelet analysis, Fig. 2, shows that the vertical profile of the zonal wind fluctuations is dominated by a wave signal with vertical wavelength of $\lambda_{z} \sim 4 \mathrm{~km}$. The meridional profile shows another signal, at higher altitude, with a lower value of vertical wavelength $\lambda_{z} \sim 2 \mathrm{~km}$. The $\lambda_{z} \sim 4 \mathrm{~km}$ signal is also found in the meridional component while decreasing the level of significance to $88 \%$. Similar analysis were performed with the Paul wavelet method with a 95\% level of significance, and gave the same results.

A clear signature of a wave with vertical wavelength of $\sim 4 \mathrm{~km}$ is seen in the profile of velocity perturbations (obtained after bandpass filtering between 1.5 and $8 \mathrm{~km}$, see 
Fig. 3, left panel) both above (13-24 km) and below (4-9 km) the jet. The vertical wavelength of the wave detected in the filtered profiles is consistent with the value derived from the wavelet analysis. On the basis of these results, we choose to apply a more selective filtering window, Fig. 3 (right), in order to get a clearer wave signal of vertical wavelength $\sim 4 \mathrm{~km}$. The phase shift and similar amplitudes of the components $u^{\prime}$ and $v^{\prime}$ in the Fig. 3 show that the wave is an IGW propagating upward above the jet $\left(u^{\prime}\right.$ is ahead of $v^{\prime}$, a quarter of cycle out of phase) and an IGW propagating downward below the jet ( $v^{\prime}$ is ahead of $u^{\prime}$, a quarter of cycle out of phase).

The same kind of phenomenon was described in Plougonven et al. (2003) using the FASTEX data, and in several other observational studies (Guest et al., 2000; Pavelin et al., 2001; Nastrom and Eaton, 2006). Note that, in comparison to the Plougonven et al. perturbation profiles, the wave propagation signatures in the present paper are reversed, as the present case studies are located in the Southern Hemisphere. Similarly to the conclusions of these references, the jet stream source seems to be a plausible source of the identified IGWs propagating above and below the jet maximum.

As was noticed above, the wavelet analysis reveals an additional, though less energetic, signal of vertical wavelength $\lambda_{z} \sim 2 \mathrm{~km}$, which appears also as small irregularities in the profile of velocity perturbations, when the $[1.5,8] \mathrm{km}$ bandpass filtering window is used (Fig. 3, left panel). This signal is also detected if a 7th-order polynomial filter is applied on the wind profiles. However, we choose not to take it into consideration, because the filtering processes reveal that this wave signal above $20 \mathrm{~km}$ is an upward propagating IGW of negligible amplitude $\left(\left|u^{\prime}\right|\right.$ and $\left|v^{\prime}\right|$ less than $\left.1 \mathrm{~m} \mathrm{~s}^{-1}\right)$.

\subsubsection{Analysis of possible sources}

Close to the Santo Domingo location, the ECMWF analyses show high-amplitude winds at the altitude $10-13 \mathrm{~km}$, as previously seen in the radiosoundings data. The jet is visible as a clear-cut high-amplitude gradient of potential vorticity (PV) on Fig. 4 (left panel). The horizontal wind field shows a similar pattern as the PV diagnostics. At lower altitudes, no significant near-surface frontal activity is detected in the winds and/or PV maps.

The jet-stream exhibits a strong curvature in the middle of the South American continent. The distribution of the corresponding Lagrangian Rossby number, on Fig. 4 (right), indicates several extended zones of ageostrophic unbalanced motion, where an emission of IGW is likely to happen. Lagrangian Rossby numbers are shown only at the altitude of the jet maximum velocity in Fig. 4 (right). Sections at different levels of the jet yield similar conclusions. The Santo Domingo region is located in the vicinity of an inflexion point in the jet-stream curved structure; there, the jet acceleration is particularly intense. The situation is quite similar to the numerical simulations of O'Sullivan and Dunkerton (1995), or the observations of Plougonven et al. (2003).
At the same time, the satellite images for the same date and location show that there was no pronounced convective activity (Fig. 5 left). The convective situation is almost identical on all satellite images taken $24 \mathrm{~h}$ before the event. Thus no significant convective activity was present in the vicinity of the radiosounding location. Convective activity is strong only in the north of the South America continent. It is known that convectively generated gravity waves can be advected by the mean flow over long distances. However this possibility is unlikely here, taking into account the direction of the winds in the previous days. Moreover, even if IGW tend to propagate more horizontally than the higher intrinsic frequency GW, the vertical component of the IGW propagation is far from being negligible. This makes the IGW possibly emitted by the northern convective cell hardly detectable in the upper troposphere and the lower stratosphere in the Santo Domingo region.

The NCEP-NCAR reanalysis of the mountain drag show no significant signal at Santo Domingo location (Fig. 5 right), which is an indication of low mountain wave activity in the region. The mountain drag diagnostic is not sufficient by itself, but the above conclusion is further confirmed by the corresponding non-hydrostatic WRF simulation. The simulated vertical velocity field shows no mountain wave features of significant amplitude (i.e. with vertical velocity amplitudes above $1 \mathrm{~m} \mathrm{~s}^{-1}$ ) which would be able to produce the IGW emission, contrary to the third case of the present study (compare Figs. 7 and 18). Furthermore, the simulated potential temperature field does not feature any area of extended folding or deformation, which is usually the case when mountain waves are propagating. Besides, no particularly strong updrafts are detected in the WRF simulations for case 1, which is consistent with the above-mentioned evidence of the lack of convection on the satellite images.

Thus, in this case, the only possible source of the IGW events observed in the upper troposphere and lower stratophere is the unbalanced jet-stream.

\subsubsection{Wave analysis in the WRF simulations}

The wind profiles measured by the radiosonde over Santo Domingo at 12:00 UTC, showing the jet stream structure with maximum velocity between $10 \mathrm{~km}$ and $11 \mathrm{~km}$, are correctly reproduced by the WRF model (Fig. 6). The WRF real-case simulations show, as was identified in the ECMWF fields, that Santo Domingo is located below an area of particularly strong zonal velocity in the jet-stream structure.

The comparison of Fig. 6 with Fig. 1 however shows that the WRF model, as could be expected, cannot reproduce the fine structure of the wind profile seen in the radiosounding data, due to better vertical resolution of the latter, and underestimates the amplitude of the fluctuations. For this reason, it was difficult to apply the same techniques as in the data analysis: the WRF vertical profiles are too smooth to enable 

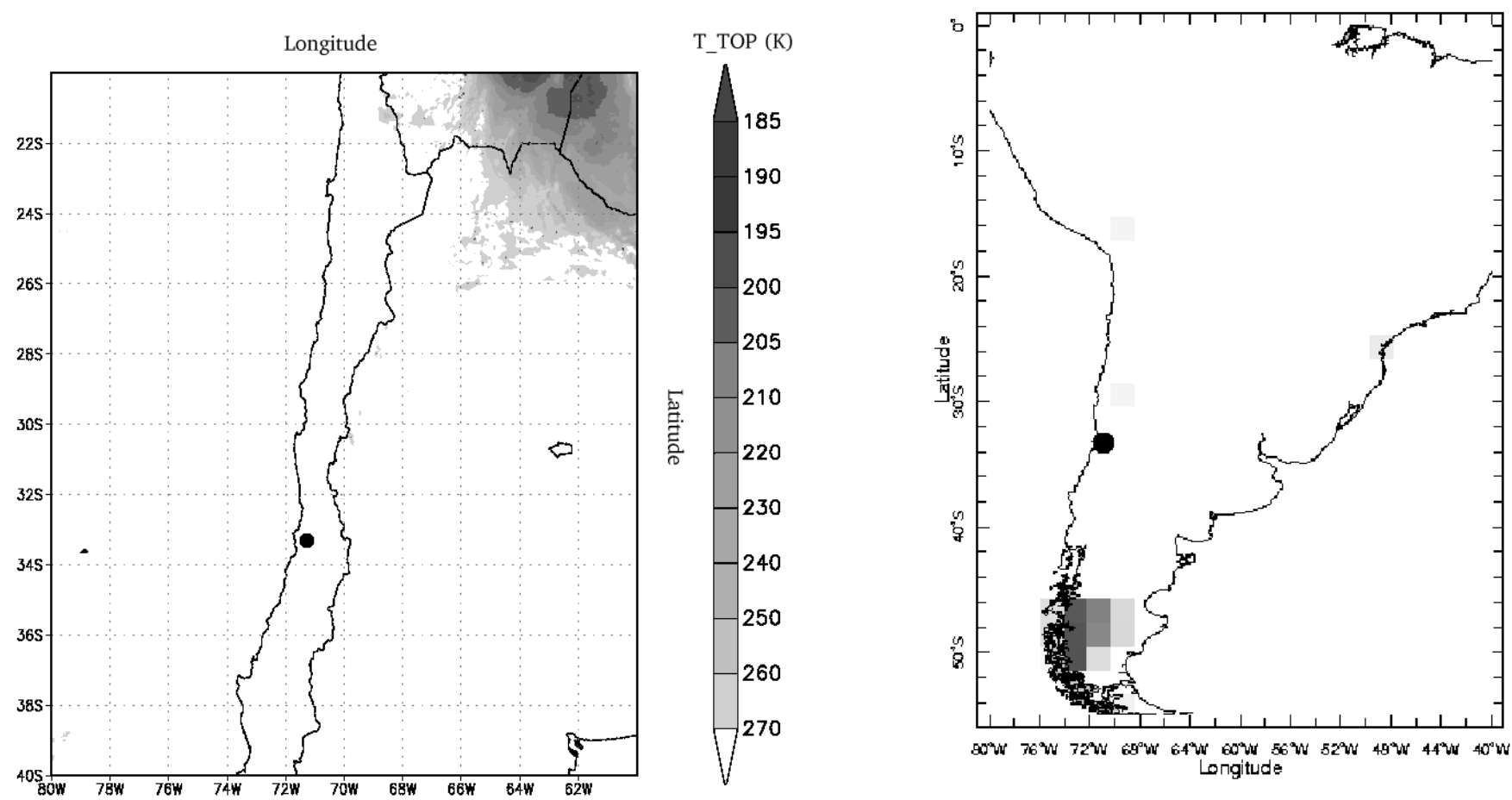

Fig. 5. Case 1: Analysis of convective and topographic IGW sources. Left: GOES satellite data, cloud top temperature field (dark zones indicate tall clouds). Right: NCEP-NCAR reanalysis, daily mean zonal gravity wave drag (darker zones correspond to stronger forcing by gravity waves). The Santo Domingo location is marked by the black dot.

a clear detection of waves by the filtering method used for the soundings profiles.

As mentioned in the previous section, the vertical wind velocity field can be used to detect the occurence of mountain waves and convective motions. Here, no particularly high vertical velocity values which could be associated with these kind of meteorological events were found (Fig. 7, left panel). In particular, no isentrope deformations and very low vertical velocities are detected at the lowest levels, confirming that the topographic source of IGW was inactive in the vicinity of Santo Domingo (which could be also expected from the moderate zonal wind amplitudes at the first levels above the ground).

Vertical velocity is also a key parameter to investigate the structure of the possible IGW events taking place in the region. In the longitude-altitude cross section of Fig. 7 (left) oscillations at altitudes between 12 and $22 \mathrm{~km}$ in the Santo Domingo region can be identified, although the vertical and horizontal wavelengths cannot be easily determined. The horizontal wavelength can however be estimated from the divergence of the horizontal wind (Fig. 7, right panel). The horizontal section confirms that a wave event is taking place in the Santo Domingo region, with the horizontal wavelength of $\lambda_{H} \sim 220 \mathrm{~km}$. In this region, the jet structure shows an inflexion point that is known to be a zone of preferential wave

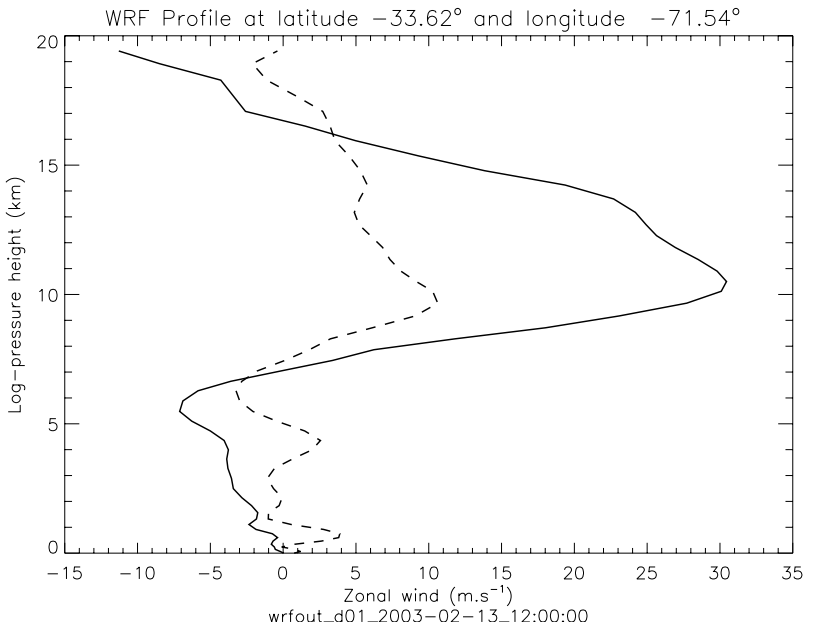

Fig. 6. Case 1: Results of the WRF simulations. Velocity profiles $\left(\mathrm{m} \mathrm{s}^{-} 1\right)$ at the nearest grid point to Santo Domingo. Full line: zonal wind, dashed line: meridional wind.

emission (cf. diagnostics in previous subsection). Hence, the WRF results, as well as the data analysis, suggest that the jet stream source is responsible for the IGW emission.

Finally, we can combine the derived parameters to check the consistency of the IGW event identified both in the 

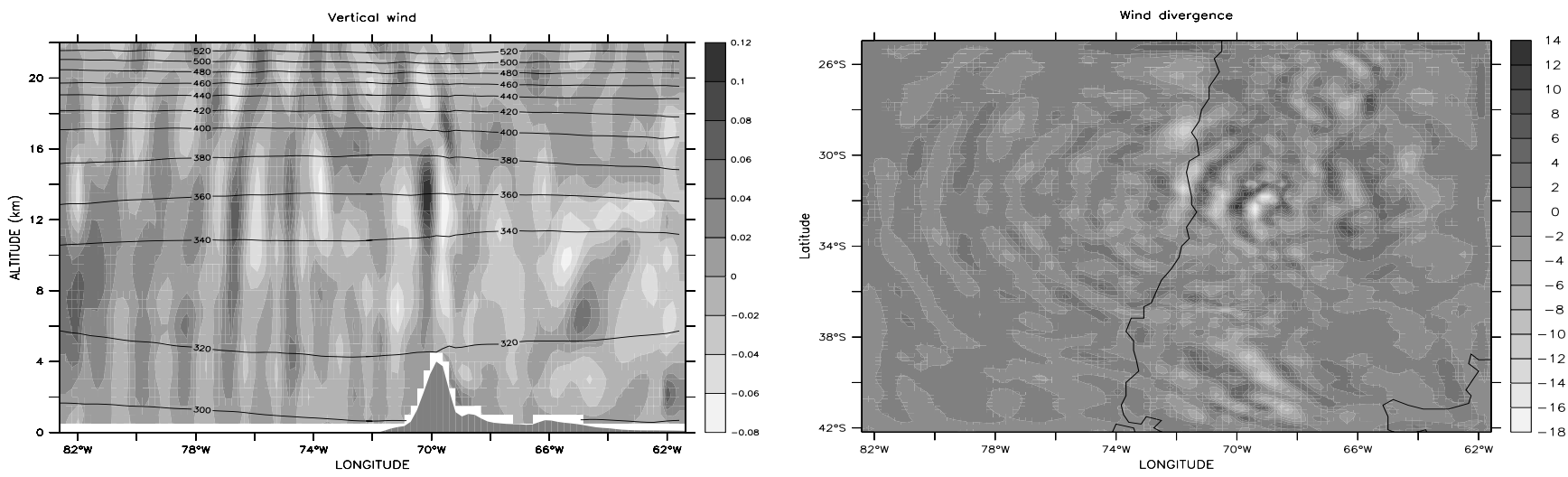

Fig. 7. Case 1: Results of the WRF simulations. Left: Vertical wind velocity ( $\mathrm{m} \mathrm{s}^{-} 1$ ) and isentropes (K). Longitude-altitude cross section at the Santo Domingo latitude. Right: Horizontal wind divergence $\left(\mathrm{s}^{-} 1\right)$. Horizontal section at the altitude $20 \mathrm{~km}$. Similar figure is obtained at lower altitudes, e.g. at $13 \mathrm{~km}$.
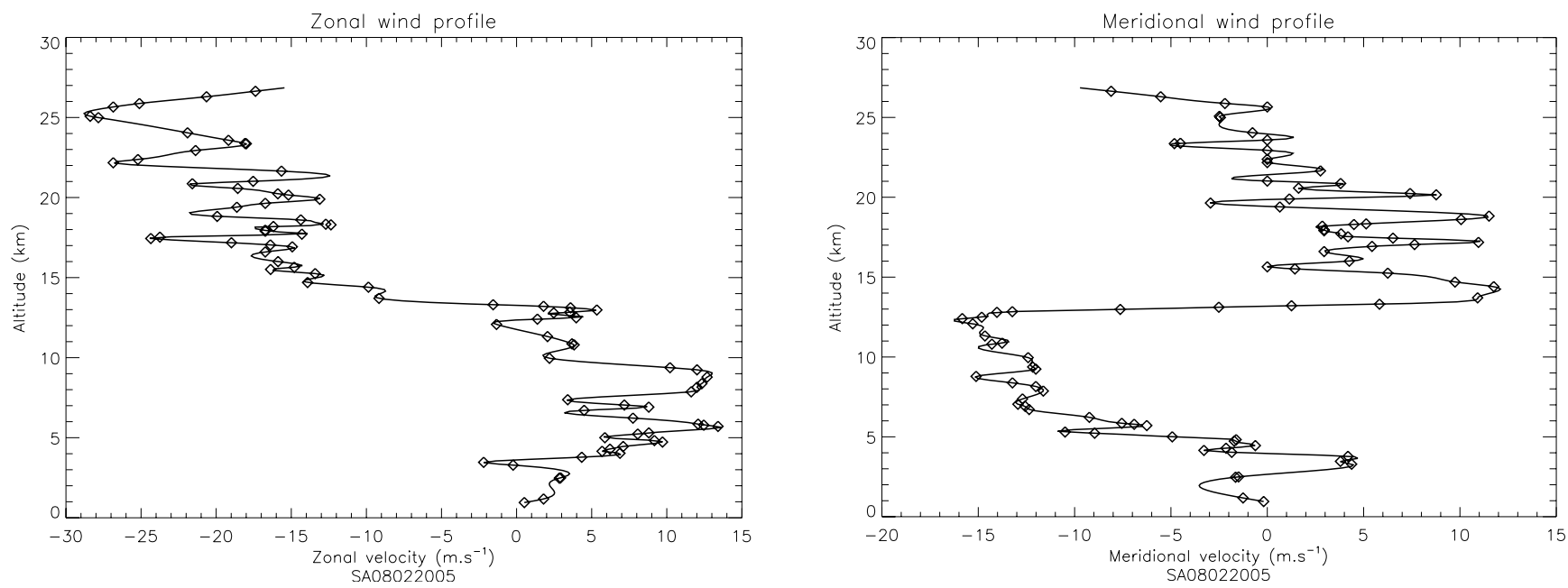

Fig. 8. Case 2: Salta radiosounding. Vertical profile of the wind velocity $\left(\mathrm{m} \mathrm{s}^{-1}\right)$. Diamonds correspond to sounding measurements. Full line is a cubic spline interpolation with vertical resolution of $100 \mathrm{~m}$. Left: Zonal wind profile. Right: Meridional wind profile.

mesoscale simulations and in the radiosounding. The intrinsic frequency $\hat{\omega}$, i.e. the frequency in the frame moving with the background flow $(\hat{\omega}=\omega-\mathbf{k} \cdot \mathbf{V}$, where $\mathbf{V}$ is the mean-flow velocity) follows from the IGW dispersion relation:

$\hat{\omega}^{2}=f^{2}+N^{2} \frac{k^{2}+l^{2}}{m^{2}}$

Here, $f$ is the Coriolis parameter, $N$ is the Brunt-Vaisala frequency with a typical stratospheric value of $0.02 \mathrm{~s}^{-1}$ consistent with the $N$ values calculated from WRF profiles, and $(k, l, m)$ are the three components of the wavevector. Given these parameters, we obtain $\sim 5 \mathrm{~h}$ for the intrinsic wave period, a typical value for the IGW event. Since we apply the dispersion relation with the vertical wavelength $\lambda_{z}$ identified in the soundings and the horizontal wavelength $\lambda_{H}$ deduced from the WRF simulations, the above calculation is no more than a check of consistency, but shows that the wave parameters are consistent with what can be expected for an IGW event.

In conclusion, the WRF simulation seems to capture well the IGW emission events, but cannot correctly reproduce all of the quantitative details revealed in the radiosoundings. It is however a useful complementary tool to get insights as to the wave characteristics.

\subsection{A case of convective source}

\subsubsection{Radiosounding data}

This case corresponds to the Salta $(24.85 \mathrm{~S}, 65.48 \mathrm{~W})$ radiosounding of 8 February 2005, 12:00 UTC (referred as case 2). The corresponding value of the Coriolis parameter 

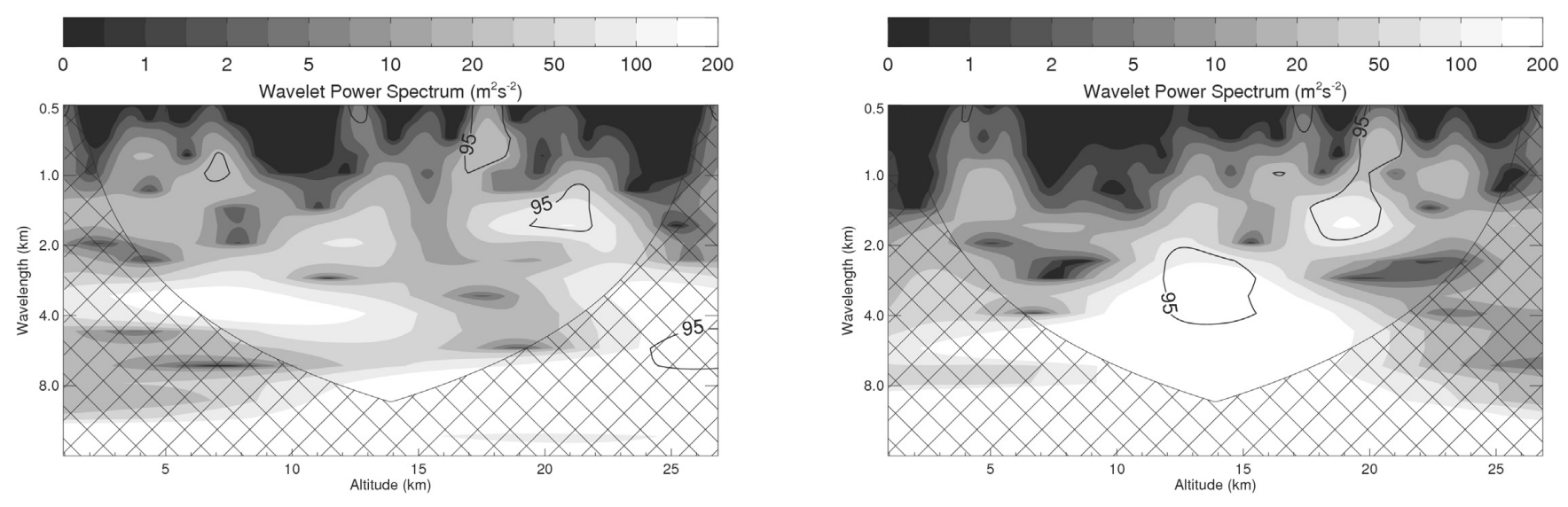

Fig. 9. Case 2: Salta radiosounding. Morlet wavelet analysis of the splined vertical velocity profiles by Torrence and Compo (1998) method. Power spectrum $\left(\mathrm{m}^{2} \mathrm{~s}^{-2}\right)$ with level of significance above $95 \%$ for dominant wavelengths and their locations. Hashed regions are out of the cone-of-significance, and should not be taken into account. Left: Zonal wind. Right: Meridional wind.

is $6.1 \times 10^{-5} \mathrm{~s}^{-1}$. The radiosoundings data are available for 86 levels almost uniformly distributed between 1 and $27 \mathrm{~km}$. The vertical profiles of the wind are presented in Fig. 8, and the results of the wavelet analysis of these profiles are shown in Fig. 9. Two distinct wave events with wavelengths $\lambda_{z} \sim 4 \mathrm{~km}$ and $\lambda_{z} \sim 1.7 \mathrm{~km}$ are identified in the meridional wind component. The zonal wind component reveals only the $\lambda_{z} \sim 1.7 \mathrm{~km}$ signal. The power spectrum of the zonal wind shows a maximum near the $\lambda_{z} \sim 4 \mathrm{~km}$ wavelength, but the level of significance of this maximum is below $85 \%$.

The velocity profile after the filtering of the mean flow is presented in Fig. 10. Results obtained with different filtering methods are consistent, and the use of the polynomial filter with and without the cubic spline interpolation of the raw profile shows no addition of spurious wave signal in the profiles, except above $21 \mathrm{~km}$. As in the previous case, a clear signature (similar amplitudes and characteristic phase lags between the horizontal wind components) of an upward propagating wave is seen in the stratosphere between 15 and $24 \mathrm{~km}$. The estimated vertical wavelength of the IGW is $\lambda_{z} \sim 1.7 \mathrm{~km}$, in good agreement with the preceding wavelet analysis. The situation is less clear in the troposphere, probably due to the reflexion of the downward propagating waves at the ground, which is presumably at the origin of the more complex structure of the signal.

In order to highlight the additional longer wave detected with the wavelet analysis, we eliminated the main signal of the $1.7 \mathrm{~km} \mathrm{IGW}$, by reducing the filtering window of the velocity profiles to $[3,8] \mathrm{km}$. The result, shown in Fig. 10 (top-right), strongly suggests that the second wave seen in the wavelet analysis is also an IGW. The IGW propagates upward above the $\sim 10 \mathrm{~km}$ altitude and downward below the $\sim 10 \mathrm{~km}$ altitude. The $\sim 10 \mathrm{~km}$ level can therefore be regarded as the probable level of the IGW emission, in good agreement with the wavelet analysis (at least in what con- cerns the meridional wind profile). We should emphasize again the consistency between the wavelet analysis and the filtering process of the velocity profiles; the two independent methods give similar results, and we checked that the velocity profiles filtered with a $[2,4] \mathrm{km}$ window do not exhibit any clear-cut IGW pattern, as it is expected from the wavelet analysis results.

\subsubsection{Analysis of possible sources}

The images in the IR channel of the satellite DMSP (Fig. 11, left panel), show the presence of a convective cell over Salta at 10:00 UTC, which moves eastward in the morning, and in the beginning of the afternoon. The maxima of horizontal wind divergence around Salta (Fig. 11, right panel) at 12:00 UTC are in good agreement with the location of the convective cells in the satellite images. The high-amplitude positive values at the $10.5 \mathrm{~km}$ altitude in the divergence map indicate the strong convective motions taking place in the Salta region. In addition, the cloud top temperature at this location, determined on the basis of TERRA-MODIS data (not shown), is $T_{\text {top }}=206 \mathrm{~K}$. This value is rather low, indicating tall clouds and intense convection. The temperature profile provided by the ECMWF reanalysis (not shown) above the convective cell, shows the top of the convective cell is at the altitude of $10-11 \mathrm{~km}$, which is consistent with the high positive amplitude of the wind divergence at this altitude. As in the previous case, the diagnostics of the gravity-wave zonal drag do not reveal any significant mountain wave activity in the vicinity of the Salta region.

The most striking feature of the synoptic situation on 8 February 2005, 12:00 UTC as given by the ECMWF analysis (Fig. 12) is a strong vertical wind shear between the 150 and $100 \mathrm{hPa}$ levels $(11.5-14 \mathrm{~km}$ ) above Salta (which is consistent with the radiosoundings, Fig. 8). This shear corresponds to 

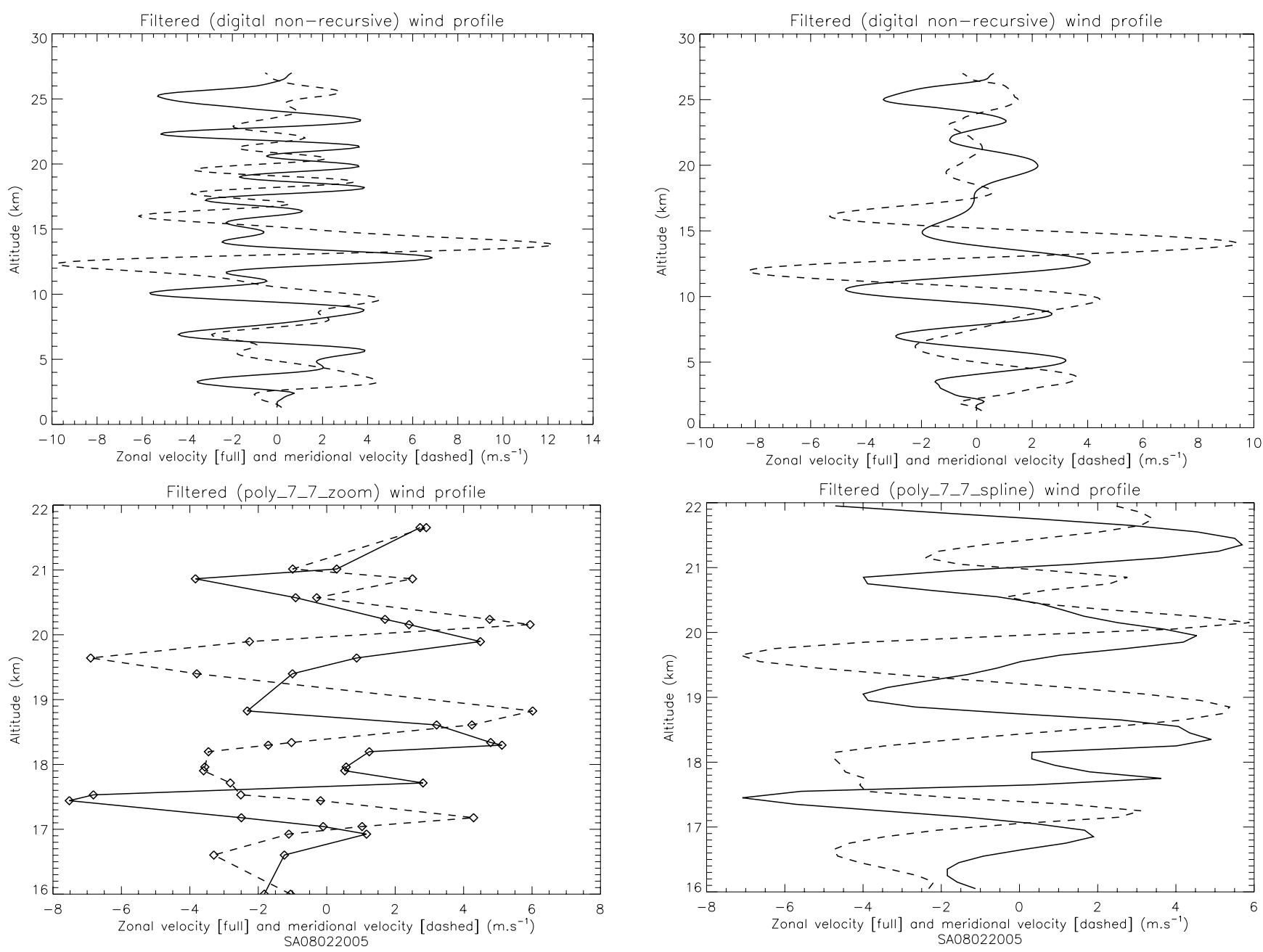

Fig. 10. Case 2: Salta Aero radiosounding. Vertical profiles of velocity perturbations $\left(\mathrm{m} \mathrm{s}^{-1}\right)$. Full line: zonal wind, dashed line: meridional wind. Top-left: Non-recursive digital filter with bandpass window of $[1.5,8] \mathrm{km}$. Top-right: Non-recursive digital filter with more restrictive bandpass window of $[3,8] \mathrm{km}$. Bottom-left: 7 th-order polynomial filter, with focus on the $16 \mathrm{~km}$ to $22 \mathrm{~km}$ altitudes (the filter is however applied to the entire vertical profile) - no cubic spline interpolation. Bottom-right: Same as bottom-left - with cubic spline interpolation.

an upper-level anticyclone, and it should not be forgotten that it could, in principle, generate the IGW by itself (Lott et al., 1992). However, the top of the above-mentioned convective cell is located just below this vertical shear of the horizontal wind; thus, the "obstacle effect" mechanism (Pfister et al., 1993) is a plausible explanation for the observed IGW event. However, no particular clue in the data analysis allows us to rule out other convective mechanisms that may trigger gravity waves (latent heating - Piani et al., 2000; or mechanical pump - Fovell et al., 1992).

No pronounced frontal activity in the region was detected in the ECMWF synoptic maps at lower levels. At higher altitudes, the potential vorticity (see levels of gray in Fig. 12) and the horizontal sections of Lagrangian Rossby number (not displayed) do not show any structured jet-stream near the Salta region. Strong ageostrophic winds can be however found at the $178 \mathrm{hPa}$ level, and could lead to IGW emission possibly detected in the Salta region northward. However, contrary to the first case study of this paper, the vertical extent of the jet southward of Salta is limited, as is the case for the vertical extent of the area of significant Lagrangian Rossby number. So the geostrophic adjustment of the jet is not ruled out southward of Salta, but the situation is not as favorable as in the first case. In addition, the strong convective motions in the vicinity of Salta suggest that it is rather unlikely that the IGW detected in the radiosounding profiles may find their origins in the unbalanced jet source $\sim 200 \mathrm{~km}$ southward. Any IGW possibly emitted by the jet southward would be hardly detectable in the Salta region circled by strong convective updrafts.

Thus, the most plausible source for the IGW detected in the Salta radiosounding is the above-mentioned convective 

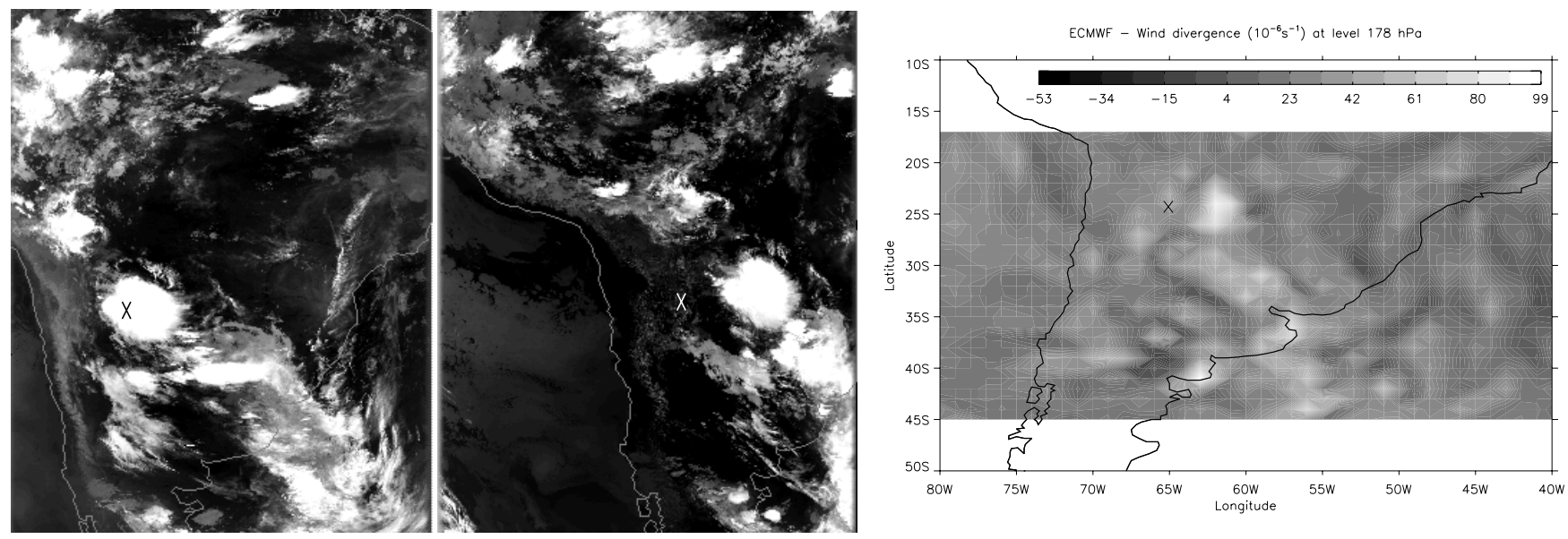

Fig. 11. Case 2: Left: Satellite images. DMSP IR satellite images at 09:55 UTC and 12:19 UTC. Right: ECMWF reanalysis. Wind convergence/divergence field $\left(\mathrm{s}^{-1}\right)$ at $12: 00 \mathrm{UTC}$ at the $178 \mathrm{hPa}$ level (altitude $\sim 10.5 \mathrm{~km}$ ). Salta location is indicated by a cross.
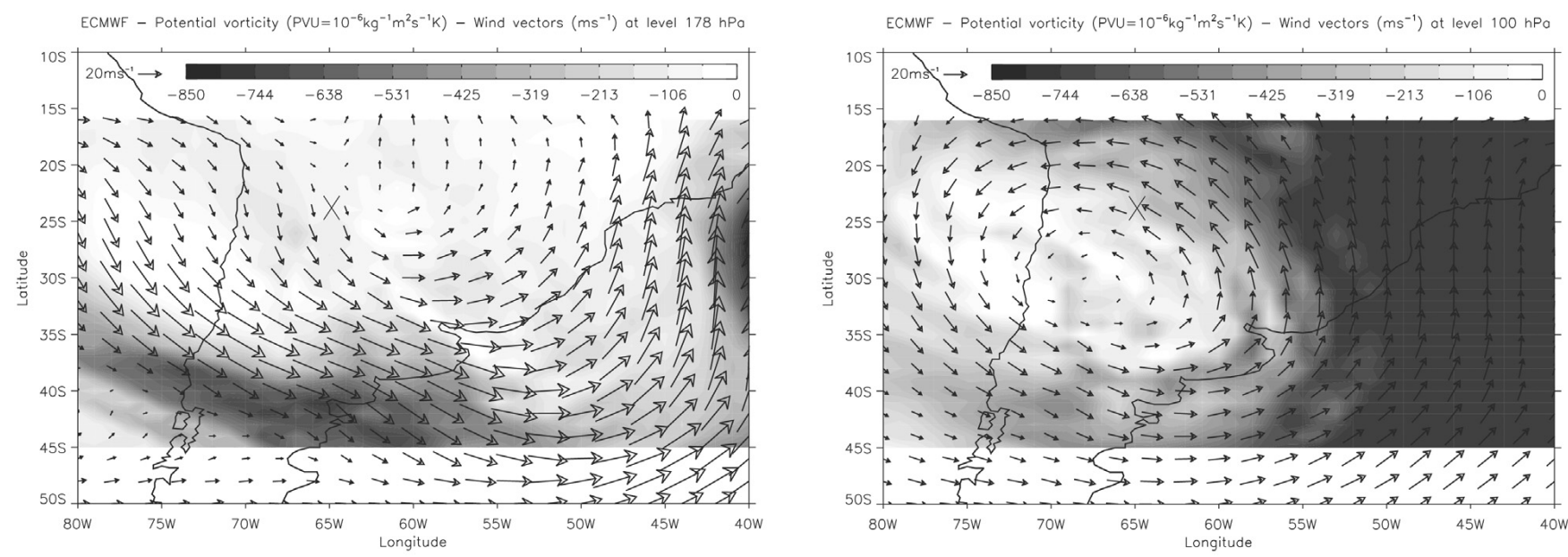

Fig. 12. Case 2: Results of the ECMWF reanalysis. Potential vorticity field (in PVU) at the $178 \mathrm{hPa}$ level (altitude $\sim 10.5 \mathrm{~km})(\mathrm{left})$ and at the $100 \mathrm{hPa}$ level (altitude $\sim 14 \mathrm{~km}$ ) (right). Values between $-850 \mathrm{PVU}$ and $0 \mathrm{PVU}$ (values respectively lower and higher than these limits are respectively black and white). Wind vectors at the corresponding levels are superimposed. Salta location is indicated by a cross.

cell. As the vertical shear of the horizontal wind is significant above the convective updrafts, the obstacle effect is plausible, but other mechanisms involving convection are not ruled out.

\subsubsection{Wave analysis in the WRF simulations}

Attempting to compare the wind profiles and wind perturbation profiles obtained from the WRF simulations and from the soundings in the precise location of Salta does not give satisfactory results. The WRF model features convection parameterizations that may not resolve all the details derived from data. The convective processes are correctly reproduced in the real-case simulations, but locations of convection triggering may vary. In the considered WRF simulation, the relative humidity in the Salta area is above $80 \%$ from the surface to an altitude of $\sim 8 \mathrm{~km}$. The humidity field is however not showing clear-cut updraft convective structures, which is consistent with the moderate vertical wind values (sections not shown).

However, east and south of Salta (where convective cells were also detected in the satellite images), a clear-cut updraft convective cell can be found, which enables clearer insights into the involved processes, even if a direct comparison with the situation highlighted in the vicinity of Salta in the observations is obviously impossible. Figure 13 shows, both in the relative humidity section and in the vertical wind section, a convective cell structure reaching the altitude of $10 \mathrm{~km}$. Upward vertical motions are rather strong, attaining the amplitude of $\sim 1 \mathrm{~m} \mathrm{~s}^{-1}$ (Fig. 14, left panel). A closer analysis of the vertical velocity field reveals oscillations above the convective cell between $10 \mathrm{~km}$ and $16 \mathrm{~km}$ in altitude. These 


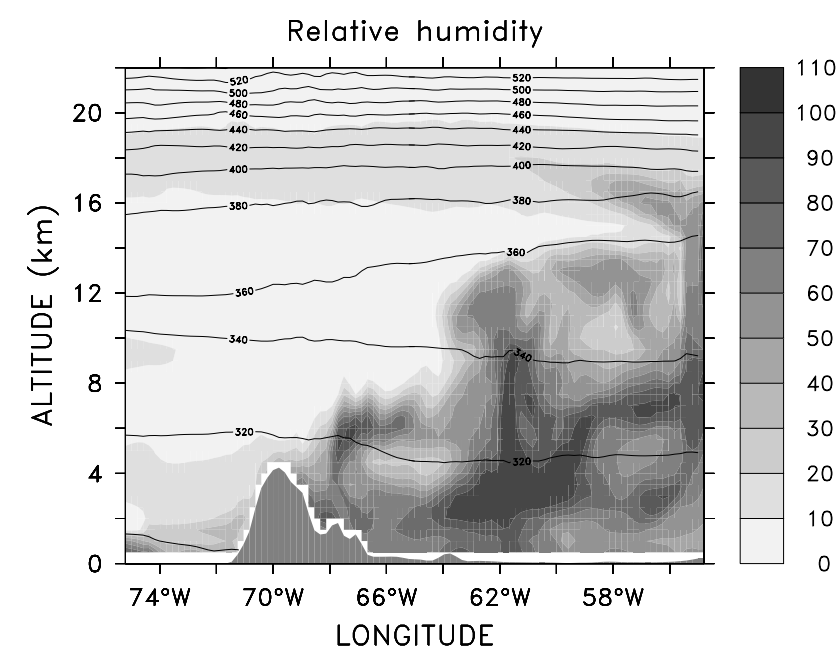

Fig. 13. Case 2: Results of the WRF simulations. Relative humidity. Longitude-altitude cross section at latitude $-29.45 \mathrm{~N}$.

oscillations are clearly detected in the divergence field of the horizontal wind (Fig. 14, right panel). This wave signal with alternating patterns of wind divergence is related to the corresponding deformation of the isentropes. The horizontal wavelength is $\sim 100-150 \mathrm{~km}$, and the vertical wavelength is $\sim 3-4 \mathrm{~km}$. According to the dispersion relation, the wave period is $\sim 2-4 \mathrm{~h}$. These values are typical of an IGW event.

Besides, the vertical extension of the convective cell can be seen in the divergence of the horizontal wind. Near the ground, at the altitude $\sim 2 \mathrm{~km}$, an extended zone of convergence is consistent with the expected wind convergence at the bottom of the convective cell. Similarly, the convective updraft top is associated to an area of enhanced positive divergence about the altitude $\sim 10 \mathrm{~km}$.

The IGW is emitted above the convective cell, where zonal and meridional velocities display a strong vertical shear (Fig. 15). These facts suggest that the IGW in this case is generated by the "obstacle effect". As the observations in a different region indicates a quite similar meteorological situation, with particularly intense and tall convective updrafts, associated with vertical shears of the horizontal wind (note the similarities between the two wind profiles Figs. 8 and 15), the IGW events identified in the WRF simulations and in the observations may have been triggered by a fairly similar mechanism, albeit the geographical location is different.

\subsection{A case of topographic source}

\subsubsection{Analysis of possible sources}

On 20 October 2002, 12:00 UTC, no convection is taking place in the Salta and Santo Domingo region, according to the satellite images. The wind in the lower troposphere over the mountains is strong (Fig. 16 left panel) and one can anticipate the appearance of large-amplitude mountain waves in the Salta and Santo Domingo region. The NCEP/NCAR reanalysis of the zonal mountain-wave drag confirms this prediction (Fig. 16 right), and indicates strong forcing by the topography, and significant amplitudes of mountain wave drag.

The quality of the Salta soundings at this day is not sufficient to enable a clear detection of waves, as was the case in the previous sections. It is generally rather difficult to find consistent soundings in the cases when the mountain wave drag in the region is strong. Occurence of mountain waves in a given region leads to intense atmospheric circulation likely to perturb, and even interrupt the radiosonde measurements at lower altitudes.

Nevertheless, the Santo Domingo soundings on 20 October 2002, 12:00 UTC (not shown) confirm the high amplitude winds identified in the ECMWF wind field. One may wonder if this low-level jet, with significant curvature as shown in Fig. 16 (left panel), may trigger IGW, according to the jet emission mechanism studied in case 1. The Lagrangian Rossby number criterion is flawed in this region, as mountain waves are also causing strong ageostrophic motion: it is impossible to separate the ageostrophic contribution from the mountain wave event and from possible imbalance of the low-level jet. However, no clear IGW signal propagating above and/or below the jet maximum (as in case 1) could be identified in the Santo Domingo radiosoundings. Assuming nevertheless that the jet source is active in the Santo Domingo region, the possibly emitted IGW will not be detectable northward in the Salta region, where these waves will be overwhelmed by the strong mountain waves forcings. Consequently, the jet stream source can be reasonably ruled out in the Salta region, and the topographical forcing is the only plausible source of IGW.

Interestingly, the Lagrangian Rossby number derived from the ECMWF reanalysis in the Salta region indicates high ageostrophic motion about the $15 \mathrm{~km}$ altitude, with values reaching 0.4 and above (Fig. 17). A secondary IGW emission, resulting from the geostrophic adjustment of the largescale flow due to the high amplitude of the main mountain wave (and, eventually, its possible breaking), may occur according to the Scavuzzo et al. (1998) mechanism. The breaking of the mountain wave at higher altitude above Salta is further suggested by the potential temperature profile from the the Salta sounding, showing a distinctive mixing layer at the $15 \mathrm{~km}$ altitude (although the bad quality of the sounding does not allow for definite conclusions). It should be reminded that, according to Lott et al. (1992), the mixing layer may emit IGW as well, in addition to the Scavuzzo et al. mechanism.

\subsubsection{Wave analysis in the WRF simulations}

The gravity-wave drag is a result of subgrid parametrizations in general circulation models, and cannot give fully reliable information on mountain wave characteristics. Similarly to the previous sections, we can use the mesoscale 

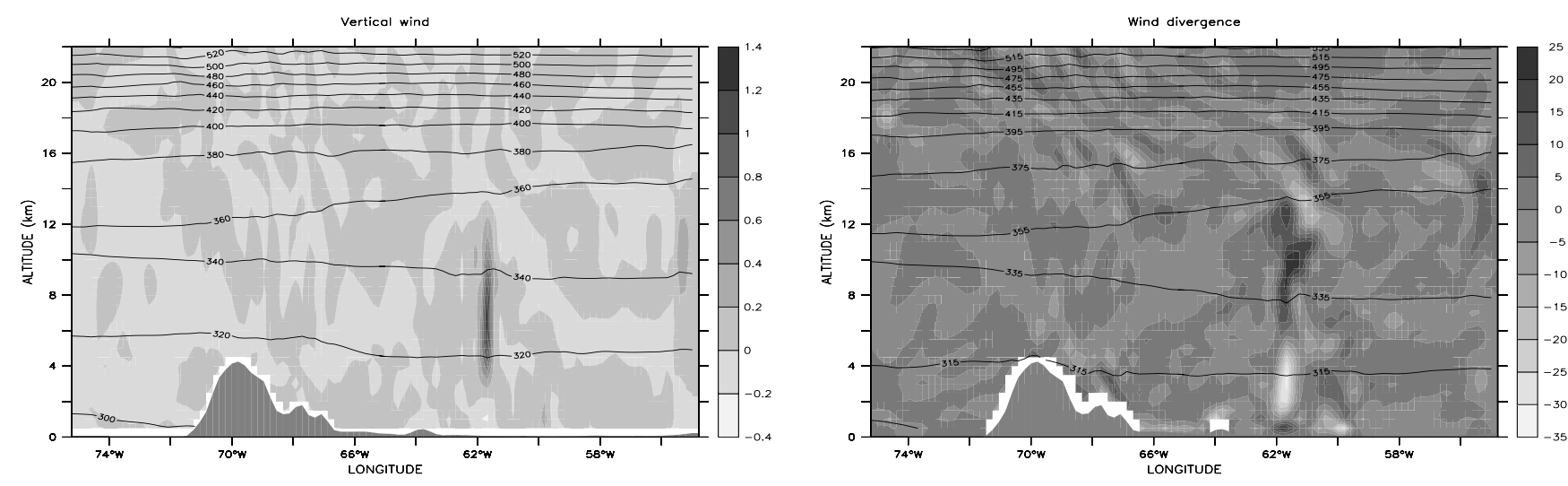

Fig. 14. Case 2: Results of the WRF simulations. Longitude-altitude cross sections at latitude $-29.45 \mathrm{~N}$. Left: Vertical wind velocity (m s${ }^{-} 1$ ) and isentropes $(\mathrm{K})$. Right: Horizontal wind divergence $\left(\mathrm{s}^{-} 1\right)$ and isentropes $(\mathrm{K})$.
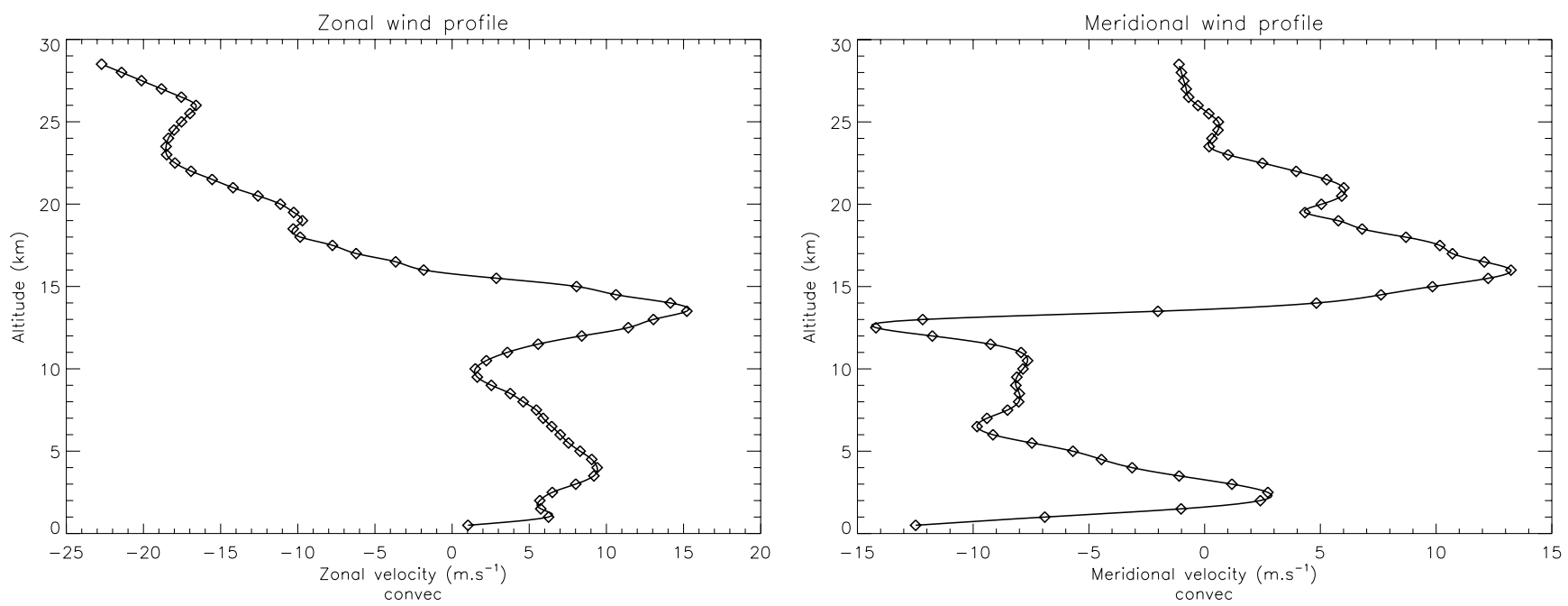

Fig. 15. Case 2: Results of the WRF simulations. Vertical profile of the wind velocity $\left(\mathrm{m} \mathrm{s}^{-1}\right)$. Diamonds correspond to WRF vertical data points. Full line is a cubic spline interpolation with vertical resolution of $100 \mathrm{~m}$. Left: Zonal wind profile. Right: Meridional wind profile.

WRF simulations to get clearer meteorological diagnostics in the region and study the emitted waves. The results of the corresponding WRF simulations (Fig. 18) show a clear-cut mountain-wave pattern in the vertical velocity and temperature distributions in the vertical plane perpendicular to the mountains. Vertical velocities derived from the WRF simulations (Fig. 18 left) show that the mountain wave event is particularly strong in the Salta region. According to the WRF simulations the mountain wave perturbation reaches the lower stratosphere $(16-19 \mathrm{~km})$, where considerable slopes of the isentropes are observed. The mountain wave at such altitudes is, probably, close to breaking, and if not, is of sufficient amplitude to induce a strong forcing in the stratosphere. Hence, the IGW emission by the mechanism proposed by Scavuzzo et al. (1998) is plausi- ble. Furthermore, according to the Scavuzzo et al. study, a significant well-defined IGW can appear if the minimal horizontal extent of the mountain wave forcing on the largescale flow is $\sim 50 \mathrm{~km}$. The high-resolution WRF simulation (Fig. 18 right) allows to accurately estimate the horizontal wavelength of the mountain wave: $\lambda_{H}^{M W} \sim 30 \mathrm{~km}$. Given that the order-of-magnitude estimate of the horizontal extent of the mountain wave forcing is $\sim 2 \lambda_{H}^{M W}$ to $\sim 4 \lambda_{H}^{M W}$ according to the same figure, the theoretical results of Scavuzzo et al. predict the IGW emission. The WRF simulations confirm that jet-stream, fronts and convective sources are not active in the region during the considered period of time, although one could not completely exclude the possibility that an IGW from a distant source had travelled a long distance to be finally detected in the Salta region. However, as mentioned 

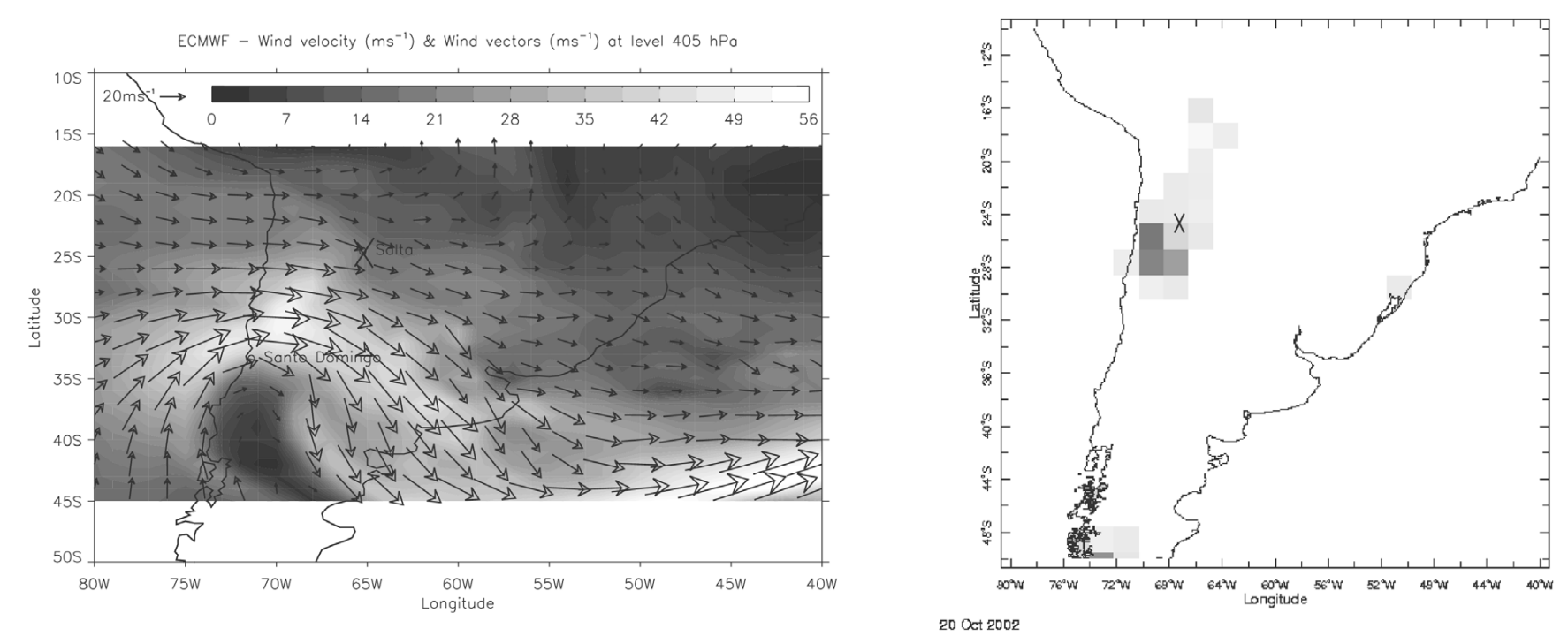

Fig. 16. Case 3: Reanalyses results. Left: ECMWF wind velocity given by the levels of grey at the $405 \mathrm{hPa}$ level (altitude $\sim 5.5 \mathrm{~km}$ ). Wind vectors at the corresponding level are superimposed. Right: NCEP-NCAR reanalysis, daily mean zonal gravity wave drag (darker zones correspond to stronger forcing by gravity waves). Salta location is indicated by a cross.

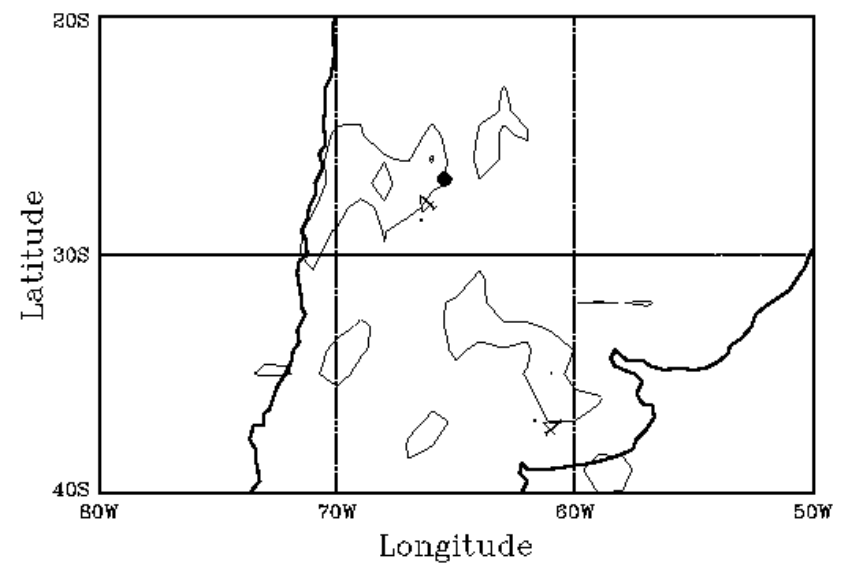

Fig. 17. Case 1: Results of the ECMWF reanalysis. Lagrangian Rossby number contours at the $15 \mathrm{~km}$ altitude. For clarity, only the values of the LR number above the threshold 0.4 are displayed. Salta is indicated by a dot.

earlier in the case of the jet-stream source, this is rather unlikely due to the oblique propagation of the IGW from its source in the vertical plane. In addition, a powerful local event like the mountain wave present in the region is much more likely to be the source of any detected IGW.

Additional oscillations above the mountain wave can be observed in the vertical velocity field if the scale is refined. However, as is the case in the previous section, using the horizontal wind divergence (Fig. 18, right panel) provides a clearer view of the oscillations patterns. The vertical velocity emphasizes the mountain wave much more than the emit- ted wave above, while the divergence of the horizontal wind emphasizes the emitted wave much more than the mountain wave below. It should be noted, in addition, that the potential temperature gradients above the maximum of the vertical velocity of the mountain wave are particularly low, indicating a mixing layer and a zone of probable mountain wave breaking. Potential temperature profile above Salta location clearly shows the mixing layer at the $15 \mathrm{~km}$ altitude (Fig. 19, left panel). The velocity perturbations profile (Fig. 19, right panel) clearly shows an IGW propagating upward at altitudes $17-21 \mathrm{~km}$, above the location of probable breaking of the mountain wave. Note that the applied alternative filtering enables the identification of both the mountain wave signal and the IGW signal above. Between 5 and $15 \mathrm{~km}$ the two components of the horizontal velocity have opposite phases, and exhibit a larger vertical wavelength, which is an indication of the stationary mountain wave (e.g. Gossard and Hooke, 1975). The wave parameters derived from Figs. 18 and 19 are typical of an IGW event: the horizontal wavelength is $\sim 150$ $200 \mathrm{~km}$, the vertical wavelength is $\sim 2 \mathrm{~km}$, and according to the dispersion relation, the wave period is $\sim 6-8 \mathrm{~h}$.

At the longitude $\sim 60 \mathrm{~W}$, another oscillation pattern can be observed above the $\sim 14 \mathrm{~km}$ altitude in Fig. 18. Even if its location is rather decorrelated from the mountain wave event, it may also be produced by the mountain wave forcing (and possible breaking) westward. This assumption is supported by the deformation pattern of the isentropes. However, since the wind a few kilometers below is rather strong, and the location is far from that of the maximum amplitude of the mountain wave, the jet stream source cannot be completely ruled out in this case. The vertical wavelength of 

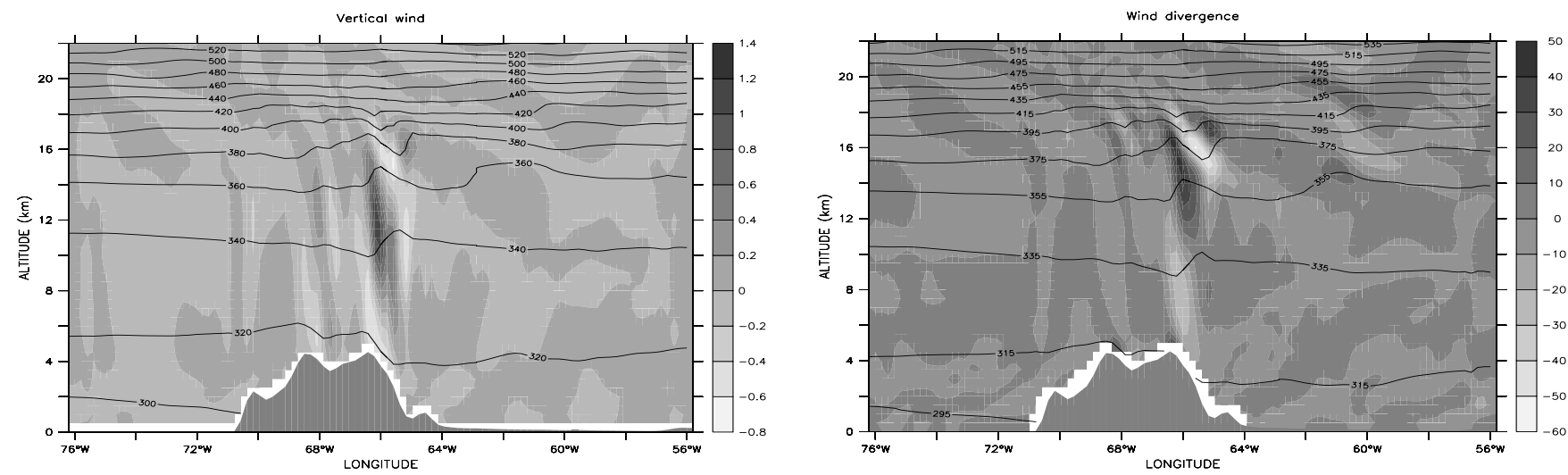

Fig. 18. Case 3: Results of the WRF simulations. Mountain wave detection in the Salta region. Longitude-altitude cross sections at latitude $-24.81 \mathrm{~N}$ (Salta latitude). Left: Vertical wind velocity $\left(\mathrm{m} \mathrm{s}^{-} 1\right)$ and isentropes $(\mathrm{K})$. Right: Horizontal wind divergence ( $\left.\mathrm{s}^{-} 1\right)$ and isentropes (K).
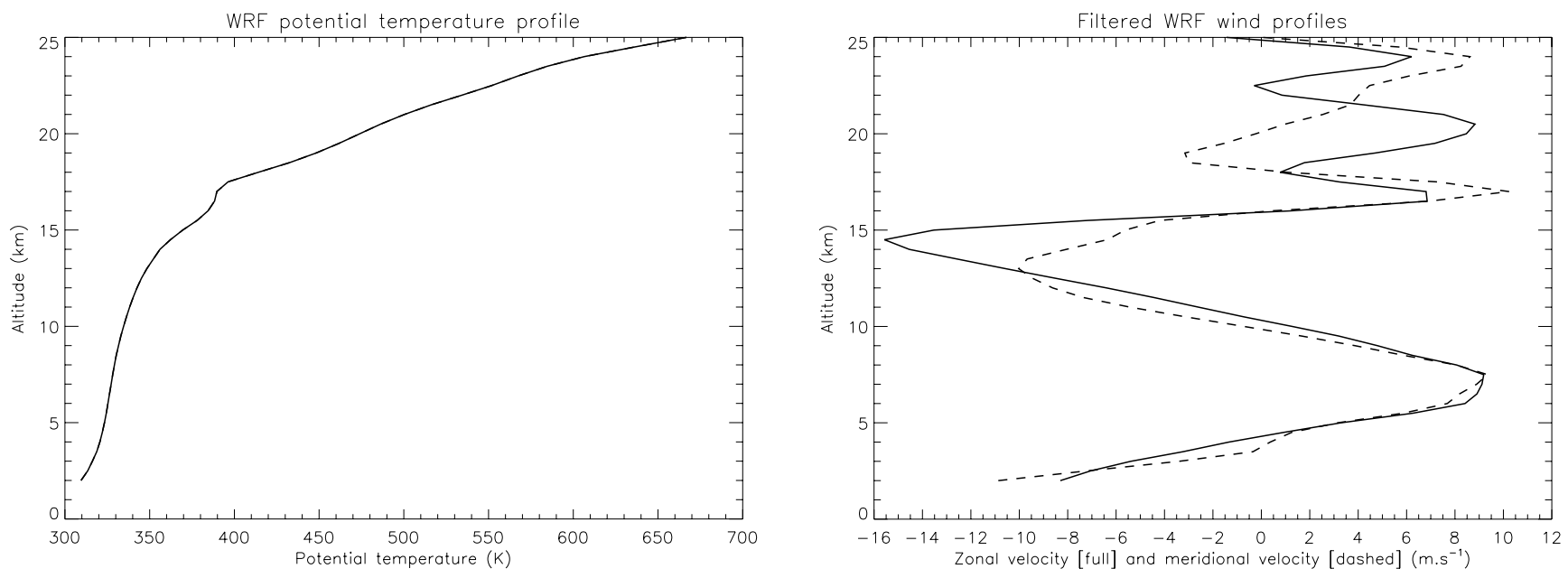

Fig. 19. Case 3: Results of the WRF simulations. Vertical profiles at Salta location. Left: Potential temperature profile (K). Right: Wind profiles $\left(\mathrm{m} \mathrm{s}^{-} 1\right)$ filtered by order 3 polynomial function, combined with a window $[2 \mathrm{~km}, \infty]$. The wind components are projected on the axes rotated in the horizontal plane in such a way that both wind components are in phase, which allows to identify the steady mountain wave pattern.

these oscillations is $\sim 5 \mathrm{~km}$, and the horizontal wavelength is below $100 \mathrm{~km}$. According to the dispersion relation estimates, the period of this wave is lower than the first IGW identified earlier.

3.4 A case of simultaneous action of topographic and convective sources

In this section, an example of simultaneous action of two different sources is briefly presented. On 9 January 2001, 21:00 UTC, the wind speed at lower atmospheric levels in the Salta region is rather strong. The WRF simulations show a mountain wave of strong amplitude in the Salta region, asso- ciated with significant deformation of the isentropes (Fig. 20, left panel). As in the purely topographic case discussed in the previous section, an IGW can be detected above the mountain wave, where the latter is close to breaking. Interestingly, eastward of the mountain wave pattern, strong convective motions are revealed in the WRF simulations. The longitude-altitude cross section of humidity enables the identification of a particularly well-developped convective cell. Inside the convective updraft, as can be seen in the vertical velocity longitude-altitude cross section, the vertical velocity is reaching $\sim 3 \mathrm{~m} \mathrm{~s}^{-1}$. As in the previous case study involving the convective cell source, a clear IGW pattern can be identified in the vertical velocity field and in the horizontal 

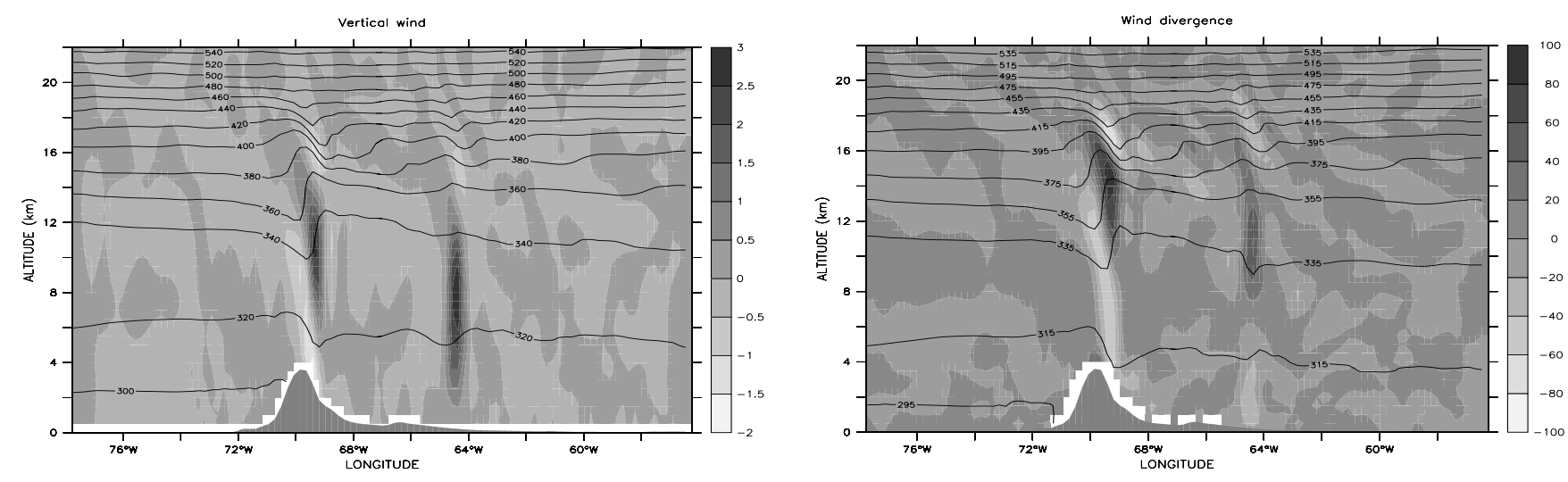

Fig. 20. Case 4: Results of the WRF simulations. Longitude-altitude cross sections at latitude $-34.28 \mathrm{~N}$. Left: Vertical wind velocity (m s ${ }^{-} 1$ ) and isentropes $(\mathrm{K})$. Right: Horizontal wind divergence $\left(\mathrm{s}^{-} 1\right)$ and isentropes $(\mathrm{K})$.

wind divergence field (Fig. 20, right panel), at the top of the convective cell updraft. Thus, the case displayed here gives an example of two different IGW in the Salta region, emitted by the topographic and convective sources, acting simultaneously.

\section{Conclusions}

We identified three events of the IGW emission by each of the three major sources in the Andes Cordillera region: jetstream, convection, and topography. All sources are recurrently in action in this area, however we found events where only one of them was clearly dominant. We also illustrated a possibility of simultaneous action of different sources. The cases of combined action of two of three sources were frequently found during this study, rendering the identification of the cases with a single dominating source rather difficult.

The IGW emission by the jet is associated with a geostrophic adjustment happening in the regions of the jet with large Lagrangian Rossby numbers, which confirms the previous diagnostics (e.g. Plougonven et al., 2003). The IGW emission by the convective source is consistent with the "obstacle" mechanism (see e.g. Pfister et al., 1993, or Alexander and Vincent, 2000), as it was accompanied by a strong shear at higher altitudes. However, other convective mechanisms like the bulk latent heat release, or direct wave emission by the wind shear, can not be excluded at this stage. The IGW emission due to topography is triggered by a mountain wave activity detected by NCEP-NCAR gravity wave drag analysis, and confirmed by high resolution WRF simulations. The mountain wave introduces strong deviations of the isentropic surfaces, and was close to breaking in the presented case. The IGW emission we observe is consistent with the mechanism proposed by Scavuzzo et al. (1998) which involves the relaxation of such state towards the thermal wind balance.
The comparison of the IGW characteristics for each source shows that the frequencies and the vertical wavelengths of the emitted waves are close, but some differences may however be reported. These results need to be completed with other case studies in order to draw more general and statistically relevant conclusions. A distinctive feature of the IGW emission by the jet-stream is a clear presence of both upward and downward propagating waves, which is not the case for the topographic and convective sources, where only upward propagating waves were reported.

The WRF simulations used to complete the diagnostics of the IGW sources and to independently estimate the characteristics of the emitted IGW, were, at the same time, good tests of this mesoscale model. They showed good performance of the WRF model, which captured systematically the emitted IGW, and enabled clearer insights into the mechanisms involved in the wave emission. The real-case mesoscale simulations, refining the hypothesis derived from data, are valuable tools for the IGW analysis and the identification of the IGW sources. In cases where the quality of radiosoundings is poor, or some information is missing, the WRF real-case simulations are of particular interest. In the case of the jetstream source, the WRF simulations completed the data analysis, providing, in particular, the horizontal structure of the IGW. In the case of the convective source, the WRF simulations allowed to characterize the IGW emitted above intense convective updrafts, and to establish their link with a highamplitude vertical shear of the horizontal wind. In the case of the mountain wave source, the WRF simulations enabled a clear separation between the MW signal, and the emitted IGW above. The mountain wave close to breaking, and the clear-cut mixing layer at the altitude of the IGW emission, were correctly reproduced by the mesoscale model.

Acknowledgements. This work was supported by the French National Programs LEFE-CHAT and LEFE-IDAO. We would like to 
thank M. Moustaoui for valuable help with the WRF simulations, as well as the two reviewers for their constructive reviews.

Topical Editor F. D'Andrea thanks two anonymous referees for their help in evaluating this paper.

\section{References}

Alexander, M. J. and Pfister, L.: Gravity wave momentum flux in the lower stratosphere over convection, Geophys. Res. Lett., 22, 2029-2032, 1995.

Alexander, M. J. and Vincent, R. A.: Gravity waves in the tropical lower stratosphere: A model study of seasonal and interannual variability, J. Geophys. Res., 105, 17 983-17 994, 2000.

Andrews, D. G., Holton, J. R., and Leovy, C. B.: Middle atmosphere dynamics, Academic Press, New York, 1987.

Dewan, E. M, Picard, R. H., O’Neil, R. R., Gardiner, H. A., Gibson, J., Mill, J. D., Richards, E., Kendra, M., and Gallery, W. O.: MSX satellite observations of thunderstorm-generated gravity waves in mid-wave infrared images of the upper stratosphere, Geophys. Res. Lett., 25, 939-942, 1998.

Eckermann, S. D. and Vincent, R. A.: VHF Radar Observations of Gravity-Wave Production by Cold Fronts over Southern Australia, J. Atmos. Sci., 50, 785-806, 1993.

Fovell, R., Durran, D., and Holton, J. R.: Numerical Simulations of Convectively Generated Stratospheric Gravity Waves, J. Atmos. Sci., 49, 1427-1442, 1992.

Fritts, D. C. and Alexander, M. J.: Gravity wave dynamics and effects in the middle atmosphere, Rev. Geophys., 41, 3-1, 2003.

Fritts, D. C. and Luo, Z.: Gravity Wave Excitation by Geostrophic Adjustment of the Jet Stream. Part I: Two-Dimensional Forcing, J. Atmos. Sci., 49, 681-697, 1992.

Fritts, D. C. and Nastrom, G. D.: Sources of Mesoscale Variability of Gravity Waves. Part II: Frontal, Convective, and Jet Stream Excitation, J. Atmos. Sci., 49, 111-127, 1992.

Gossard, E. E. and Hooke, W. H.: Waves in the atmosphere. Elsevier Scientific Publishing, 1975.

Guest, F. M., Reeder, M. J., Marks, C. J., and Karoly, D. J.: Inertiagravity waves observed in the lower stratosphere over Macquarie Island, J. Atmos. Sci., 57, 737-752, 2000.

Hertzog, A., Souprayen, C., and Hauchecorne, A.: Observation and backward trajectory of an inertio-gravity wave in the lower stratosphere, Ann. Geophys., 19, 1141-1155, 2000, http://www.ann-geophys.net/19/1141/2000/.

Lane, T. P. and Knievel, J. C.: Some Effects of Model Resolution on Simulated Gravity Waves Generated by Deep, Mesoscale Convection, J. Atmos. Sci., 62, 3,408, 2005.

Lane, T. P., Reeder, M. J., and Clark, T. L.: Numerical Modeling of Gravity Wave Generation by Deep Tropical Convection, J. Atmos. Sci., 58, 1249-1274, 2001.

Lott, F., Kelder, H., and Teitelbaum, H.: A transition from KelvinHelmholtz instabilities to propagating wave instabilities, Phys. Fluids, 4, 1990-1997, 1992.

Moustaoui, M., Teitelbaum, H., van Velthoven, P. F. J., and Kelder, H.: Analysis of Gravity Waves during the POLINAT Experiment and Some Consequences for Stratosphere-Troposphere Exchange, J. Atmos. Sci., 56, 1019-1030, 1999.

Nastrom, G. D. and Eaton, F. D.: Quasi-monochromatic inertia-gravity waves in the lower stratosphere from
MST radar observations, J. Geophys. Res., 111, 19103, doi:10.1029/2006JD007335, 2006.

Nastrom, G. D. and Fritts, D. C.: Sources of Mesoscale Variability of Gravity Waves. Part I: Topographic Excitation, J. Atmos. Sci. 49, 101-110, 1992.

O'Sullivan, D. and Dunkerton, T. J.: Generation of Inertia-Gravity Waves in a Simulated Life Cycle of Baroclinic Instability, J. Atmos. Sci., 52, 3695-3716, 1995.

Orlanski, I.: A rational subdivision of scale for atmospheric processes, B. Am. Meteorol. Soc., 56, 527-530, 1975.

Pavelin, E., Whiteway, J. A., and Vaughan, G.: Observation of gravity wave generation and breaking in the lowermost stratosphere, J. Geophys. Res., 106, 5173-5180, 2001.

Pfister, L., Scott, S., Loewenstein, M., Bowen, S., and Legg, M.: Mesoscale Disturbances in the Tropical Stratosphere Excited by Convection: Observations and Effects on the Stratospheric Momentum Budget, J. Atmos. Sci., 50, 10581075, 1993.

Piani, C., Durran, D., Alexander, M. J., and Holton, J. R.: A Numerical Study of Three-Dimensional Gravity Waves Triggered by Deep Tropical Convection and Their Role in the Dynamics of the QBO, J. Atmos. Sci., 57, 3689-3702, 2000.

Plougonven, R. and Snyder, C.: Inertia-gravity waves spontaneously generated by jets and fronts. Part I: Different baroclinic life cycles, J. Atmos. Sci., 64, 2502-2520, 2007.

Plougonven, R., Teitelbaum, H., and Zeitlin, V.: Inertia gravity wave generation by the tropospheric midlatitude jet as given by the Fronts and Atlantic Storm-Track Experiment radio soundings, J. Geophys. Res., 108, 4686-4704, 2003.

Press, W. H., Flannery, B. P., Teukolsky, S. A., and Vetterling, W. T.: Numerical Recipes in C: The Art of Scientific Computing, Cambridge University Press, 1992.

Reeder, M. J. and Griffiths, M.: Stratospheric inertia-gravity waves generated in a numerical model of frontogenesis. II: Wave sources, generation mechanisms and momentum fluxes, Q. J. Roy. Meteorol. Soc., 122, 1175-1195, 1996.

Sato, K., Hashiguchi, H., and Fukao, S.: Gravity waves and turbulence associated with cumulus convection observed with the UHF/VHF clear-air Doppler radars, J. Geophys. Res., 100, 7111-7120, 1995.

Scavuzzo, C. M., Lamfri, M. A., Teitelbaum, H., and Lott, F.: A study of the low-frequency inertio-gravity waves observed during the Pyrénées Experiment, J. Geophys. Res., 103, 17471758, 1998.

Skamarock, W. C., Klemp, J. B., Dudhia, J., Gill, D. O., Barker, D. M., Wang, W., and Powers, J. G.: A description of the Advanced Research WRF, version 2, Natl. Cent. for Atmos. Res. Tech. Note, 468+STR,, 2005.

Snyder, C., Skamarock, W. C., and Rotunno, R.: Frontal Dynamics near and following Frontal Collapse, J. Atmos. Sci., 50, 3194 3212, 1993.

Thomas, L., Worthington, R. M., and McDonald, A. J.: Inertiagravity waves in the troposphere and lower stratosphere associated with a jet stream exit region, Ann. Geophys., 17, 115-121, 1999, http://www.ann-geophys.net/17/115/1999/.

Torrence, C. and Compo, G. P.: A Practical Guide to Wavelet Analysis, B. Am. Meteorol. Soc., 79, 61-78, 1998.

Uccellini, L. W. and Koch, S. E.: The synoptic setting and possible 
energy sources for mesoscale wave disturbances, Mon. Weather Rev., 115, 721-729, 1987.

Van Tuyl, A. H. and Young, J. A.: Numerical simulation of nonlinear jet streak adjustment, Mon. Weather Rev., 110, 20382053, 1982.
Vincent, R. A. and Alexander, M. J.: Gravity waves in the tropical lower stratosphere: An observational study of seasonal and interannual variability, J. Geophys. Res., 105, 17 971-17 982, 2000.

Zhang, F., Koch, S. E., Davis, C. A., and Kaplan, M. L.: A survey of unbalanced flow diagnostics and their application, Adv. Atmos. Sci., 17, 165-183, 2000. 